\title{
A Reappraisal of the Chronology of the Chalcolithic Period in SE Iran: Absolute and Relative Chronology of Tepe Dehno and Tepe East Dehno, Shahdad
}

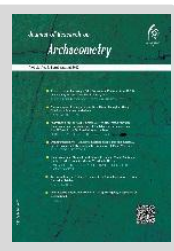

\author{
Nasir Eskandari*
}

Assistant Professor, Department of Archaeology, University of Jiroft, Jiroft, IRAN

\begin{abstract}
Archaeologically, eastern Iran is poorly known compared to the other regions of Iranian Plateau. Hence, there are many unanswered questions regarding the prehistoric chronological table of this region. The present knowledge of prehistoric cultures and chronology of Southeastern Iran is mostly through based on the 1960s archaeological excavations. In particular, the common chronology of the Chalcolithic period in SE Iran is exclusively based on the dates from old excavations at two sites of Tepe Yahya in Soghun valley and Tal-I Iblis in Bardsir plain. Due to the exciting discovery of major Bronze Age urban centers in southeastern Iran, such as Shahr-e Sokhte, Shahdad and Konar Sandal (Jiroft), most scholarly attention has been given to the $3^{\text {rd }}$ millennium BC. As a result, the cultures preceding and posterior the Bronze Age have been often neglected. Recent project of Dasht-e Lut resulted in new information on the chronology of the prehistory of SE Iran. This paper is intended to expose 10 radiocarbon data from recent excavations at two prehistoric sites on the west of Lut desert, Shahdad area in Kerman province. Recent excavations at Tepe Dehno and Tepe East Dehno in Shahdad plain have revealed levels dating back a period from the early $5^{\text {th }}$ to early $3^{\text {rd }}$ millennium BCE based on ${ }^{14} \mathrm{C}$ absolute dates. Tepe Dehno is a large site is located about one kilometer from the east of the Bronze Age urban site of Shahdad. It is a shallow large mound, surrounded by several small solitaire mounds. It is founded on the top of a natural hill. The site is approximately 20 hectares in extent and rises $8 \mathrm{~m}$ above the level of the surrounding land. In term of occupational sequence, excavation at Tepe Dehno established three main occupation periods so far which they are labeled from the oldest to the youngest Dehno I-III. These periods were distinguished based on ceramic evidence and absolute dates. Dehno I period as the earliest occupation corresponds to late fifth millennium BC (4250-4000 B.C) was identified in trench IV. The second period was documented through excavations at trenches I \& II; Dehno II period is related to mid to late fourth millennium BC (3700-3300 BC), known as Aliabad (Iblis IV) culture. Dehno III period (3200-2900/2800 BC) is a hitherto unknown period that came from 2 charcoal samples from Trench III. Tepe East Dehno is a prehistoric site located $700 \mathrm{~m}$ east of the site of Tepe Dehno. Two radiocarbon dates from this trench indicate that the occupation of Tepe East Dehno falls into the first half of the fifth millennium. In this paper, based on both new absolute dates and comparative relative chronology, I attempted to appraise critically the chronology of the Chalcolithic period of SE Iran and finally an updated chronological table of the period was presented. A total of 10 radiocarbon charcoal samples from the mentioned excavated sites were analyzed using Accelerator Mass Spectrometer (AMS) method. Radiocarbon determinations from the excavated sites have provided this opportunity to revise the prehistoric
\end{abstract}

${ }^{*}$ Corresponding author: nasir.eskandari@ujiroft.ac.ir 
chronology of South-East Iran. Evidence illustrated that the old chronology of Southeastern Iran needs a principal revision.

Keywords: Southeastern Iran, Shahdad, ${ }^{14} \mathrm{C}$ Dating, AMS, Chronological Table. 


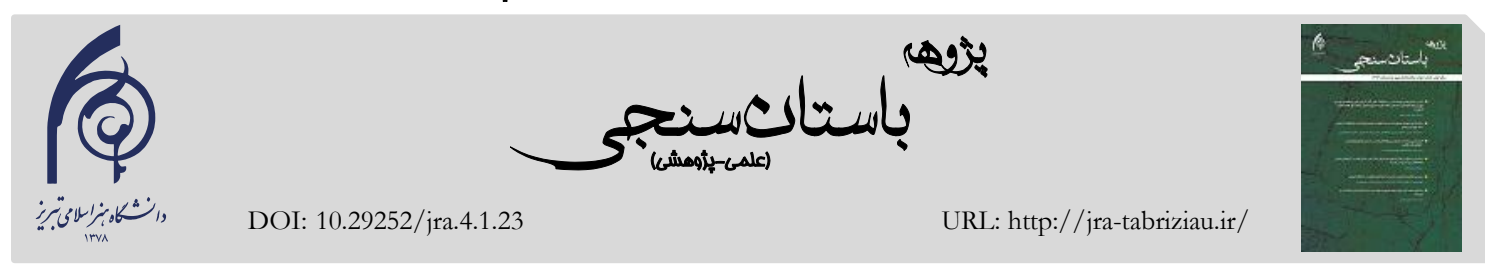

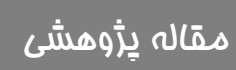

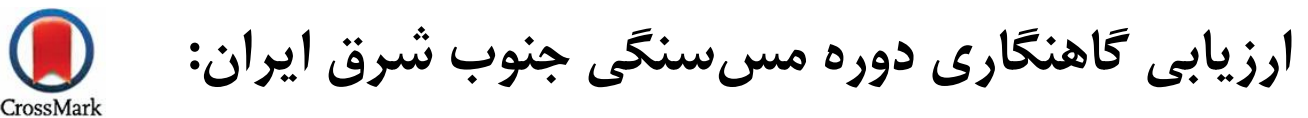

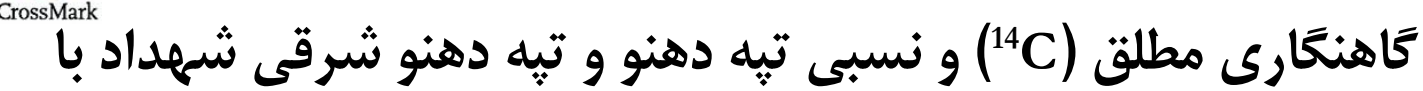 استفاده از روش طيفسنج جرمى شتابدهنده (AMS)
}

\author{
نصير اسكندرى " نصان \\ استاديار گروه باستانشناسى، دانشگاه جيرفت، جيرفت، ايران
}

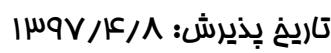

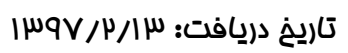

جكيده

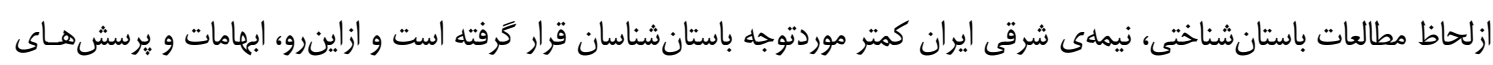

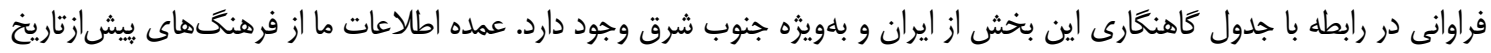

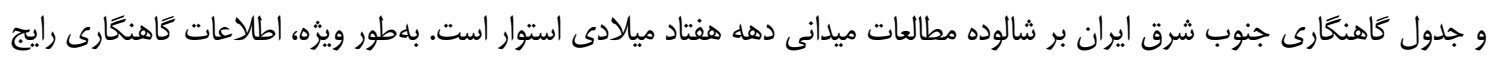

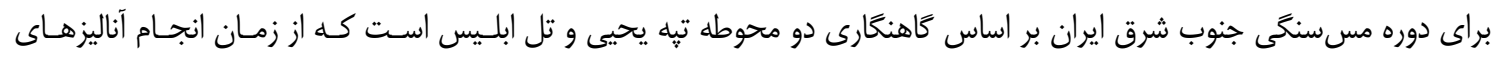

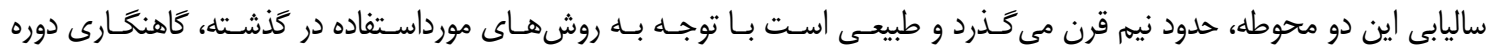

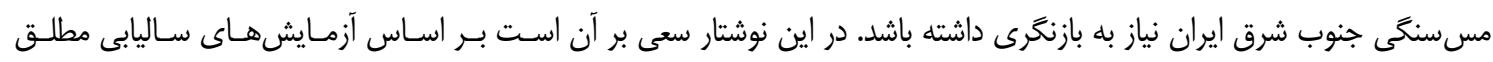

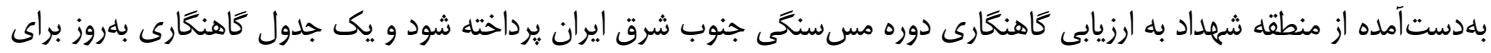

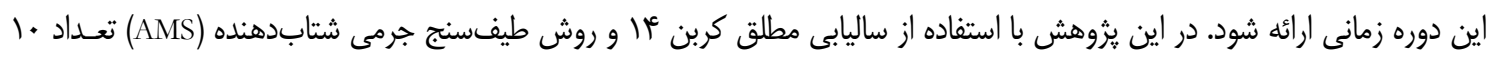

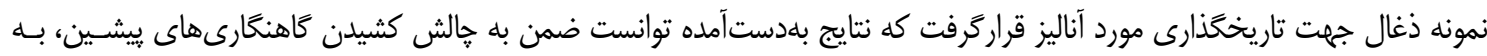

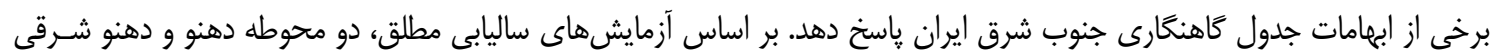

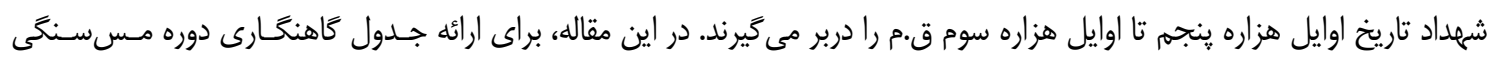

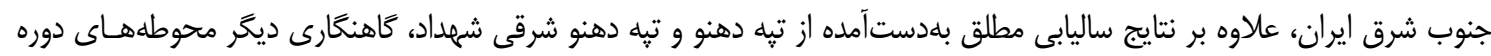
مس جنَى جنوب شرق كه بلتازگى كاوش شدهاند؛ نظير محوطه محطوط آباد و محوطه ورامين جيرفت نيز موردتوجه قرار گرَفتهاند. وازَّان كليدى: جنوب شرق ايران، شهداد، جدول كاهنغارى، ساليابى كربن عا به روش AMS.

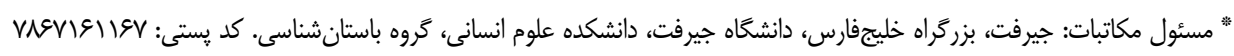

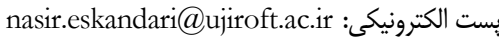

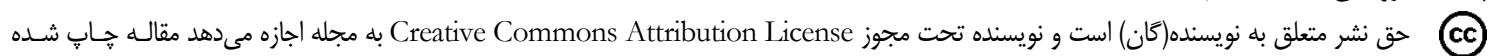
را با ديكران به اشتراك بخذارد منوط بر اينكه حقوق مؤلف اثر حفظ و به انتشار اوليه مقاله در اين مجله اشاره شود. 
فعاليت جدى بر روى دورههـاى يــيش از عصــر مفــرغ در

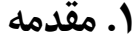

منطقه انجام نشده است. بر اين اساس، فصـل يهـاردهم فعاليتهاى باستانشناختى دشت لوت عمدتاً در اين راستا

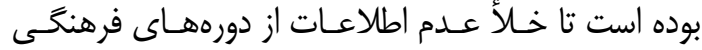
ييش از عصر مفرغ منطقه شهداد را ير كنـد. ازايسنرو، دو محوطه يِيشازتاريخى تبه دهنو و دهنو شرقى در دشـت

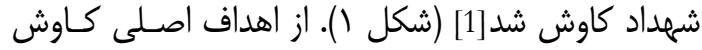

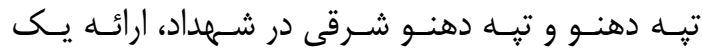

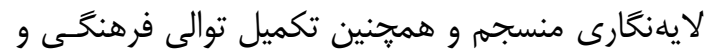

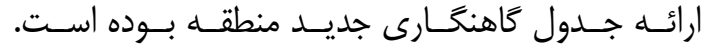

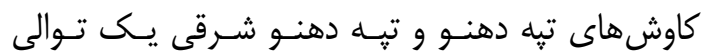

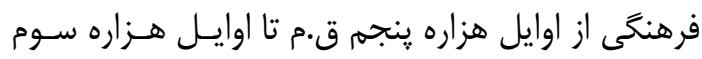
ق.م را ارائه كرد. تاريخهاى ارائه شده بر اساس • • أمونه

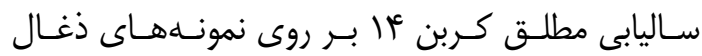
بهدست آمده از جهار ترانشه كاوش شده در تيـهـ دهنـو و يك ترانشه كاويده شده در تِّه دهنو شرقى است. نتسايج

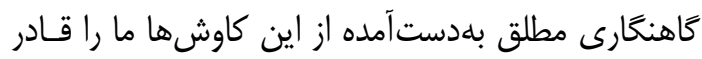

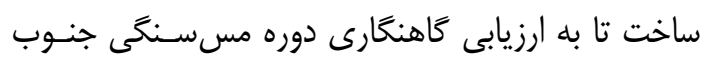
شرق ايران بيردازيم.

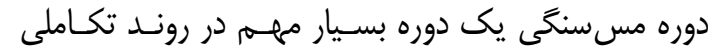
فرهنگهاى بيشازتاريخى منطقه جنوب شرق ايران بوده

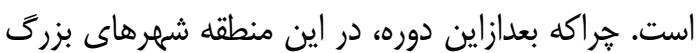

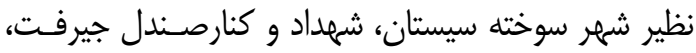

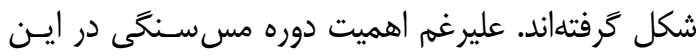

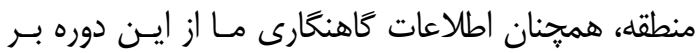
كاوشهاى قديمى تنها دو محوطه تِّه يحيى و تل ابليس إنسات

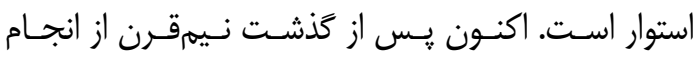

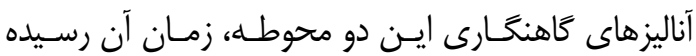

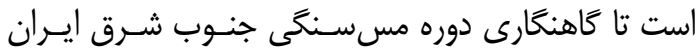

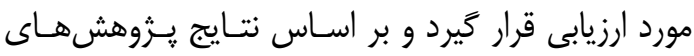

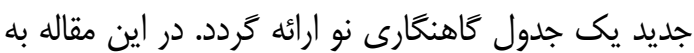

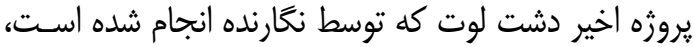

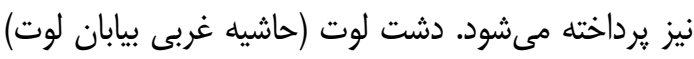

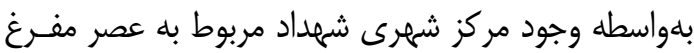

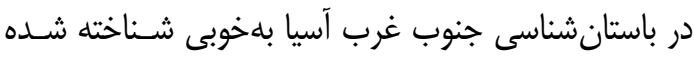

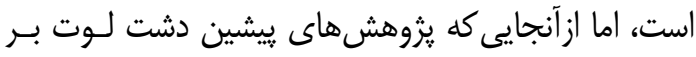
روى محوطه عصر مفرغى شهمداد متمركز بـوده، هـيجيج

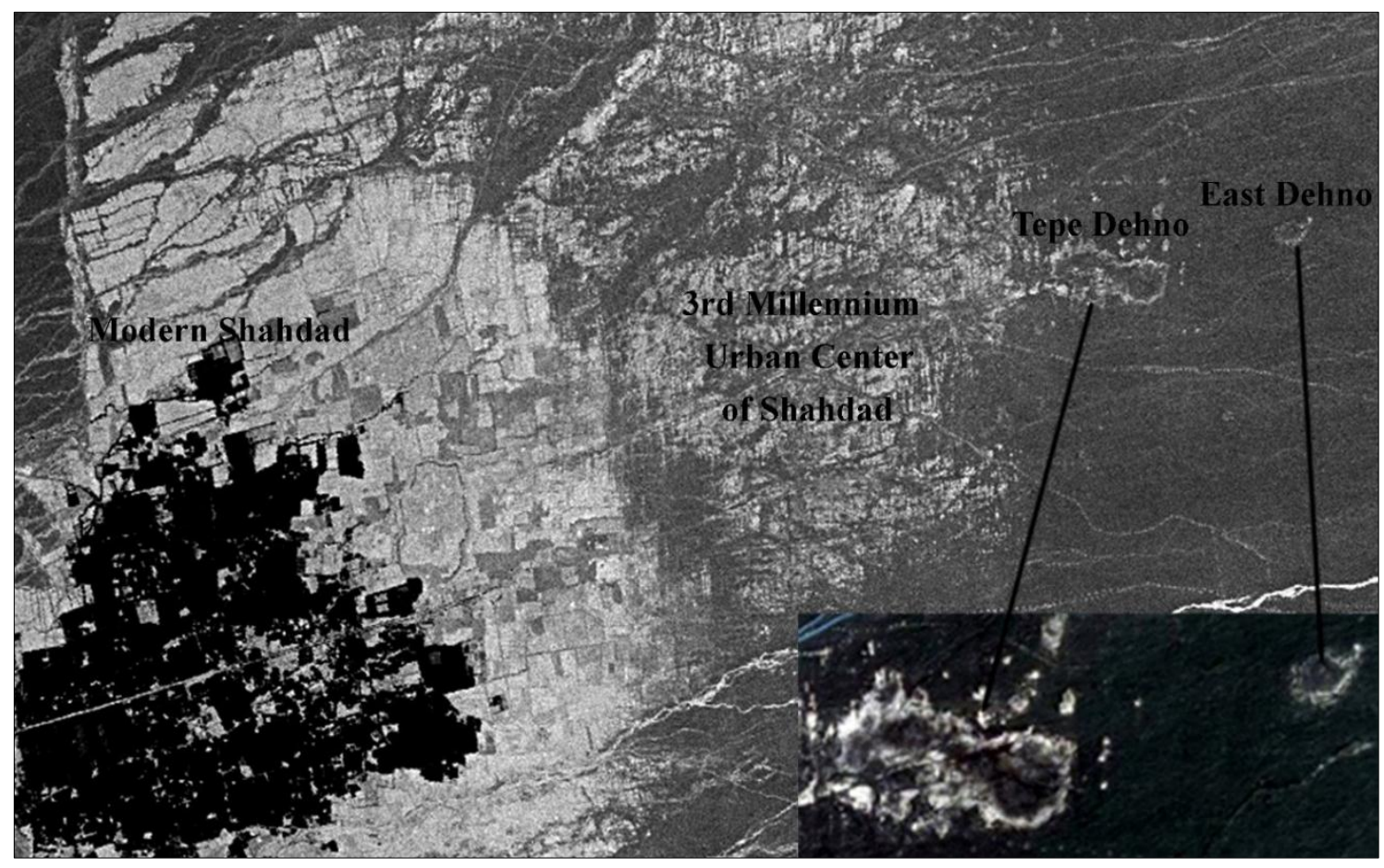

شكل ا: تصوير كورنا نشاندهندهى موقعيت تبه دهنو و تبه دهنو شرقى نسبت به محوطه شهداد

Fig. 1: Satellite image showing the location of Tepe Dehno and East Dehno to the east of modern Shahdad 
كاهنغارى دوره مـسســــى در جنـوب شـرق ايـران بـا

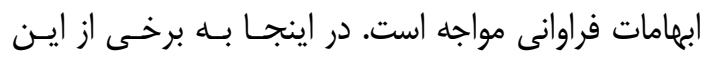
ابهامات و مشكلات يرداخته مى شود. در تل ابليس، سه دوره اوليـه (0, I \& II) بـر اسـاس دئس

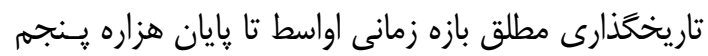

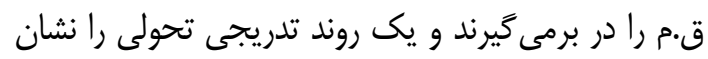

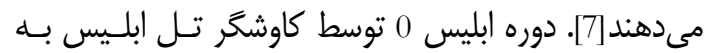

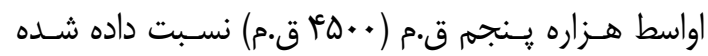

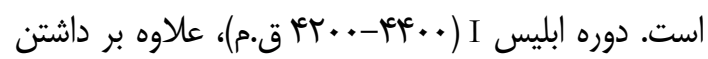

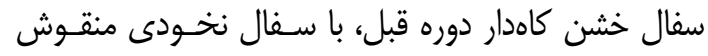

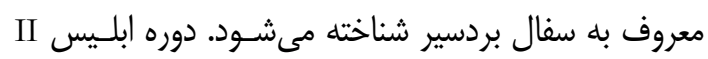

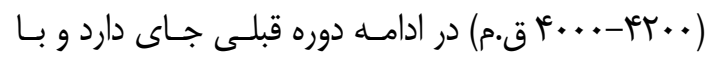

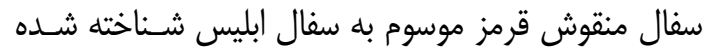

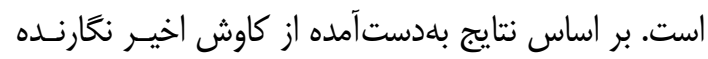

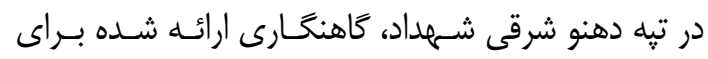

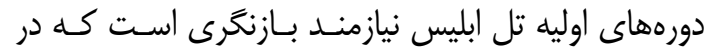
ادامه بدان يرداخته مىشود. در تيه يحيى دورههـاى اوليـه (VII, VI \& V)

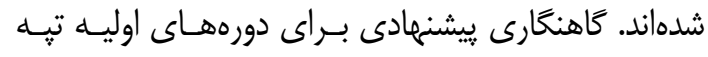

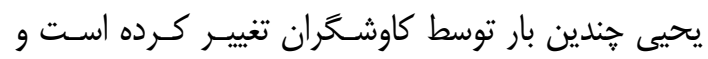

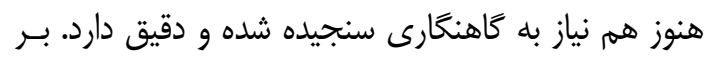

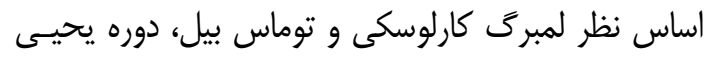
ق. تله (.) VII

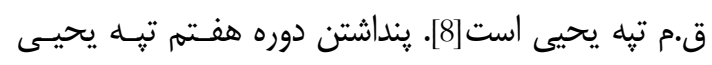

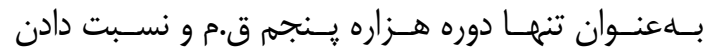

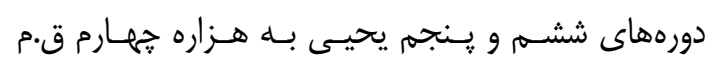

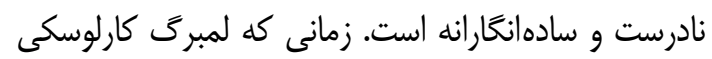

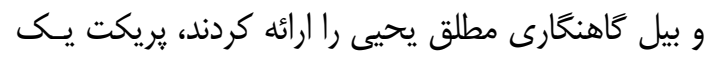

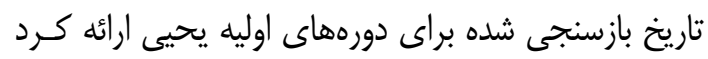

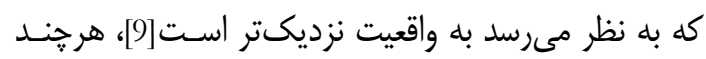

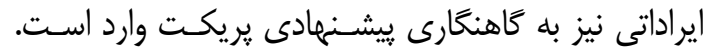

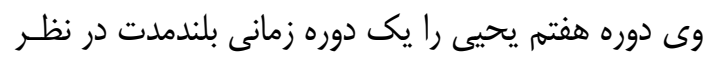

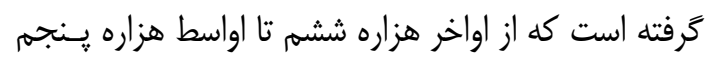

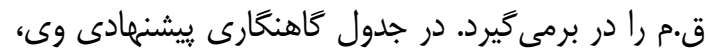

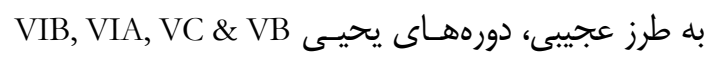

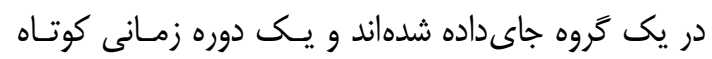

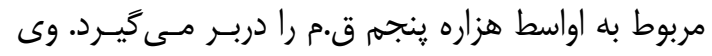

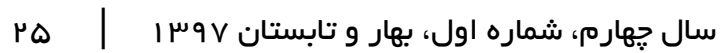

r. بيشينه تحقيق؛ مشكلات كَاهنًَارى دوره مس سنكَى جنوب شرق ايران

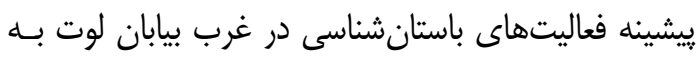

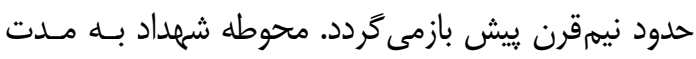

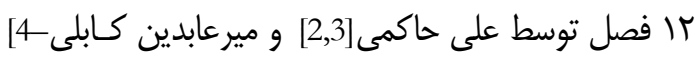

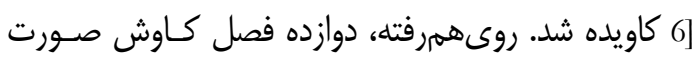

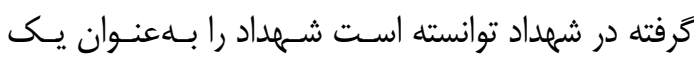
مركز مهرم شهرى در عصر مفرغ فلات ايران مطرح كنـــ

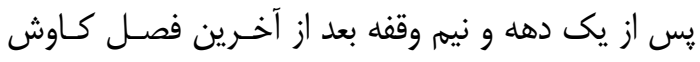

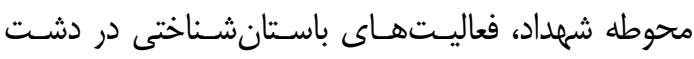

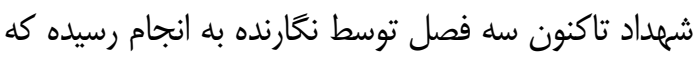

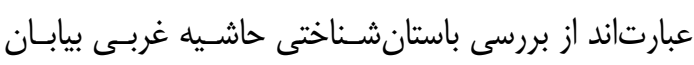

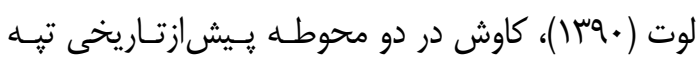

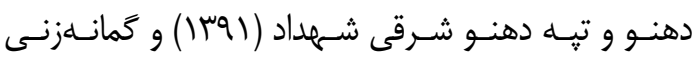

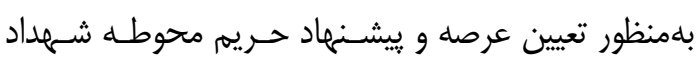

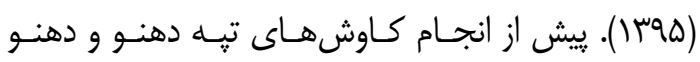

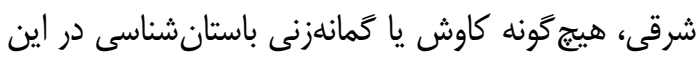

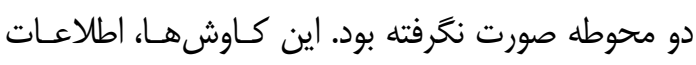

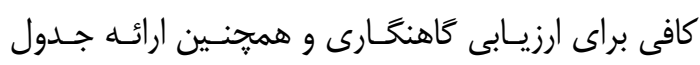

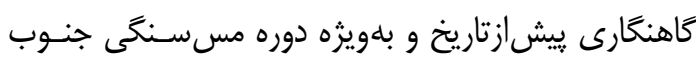

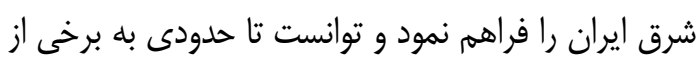

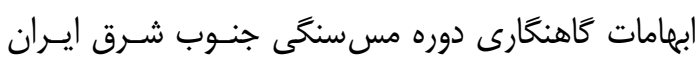
ياسخ دهد. دوره مسسنكى دوره زمانى مهمى در رونــد تكـاملى إنى

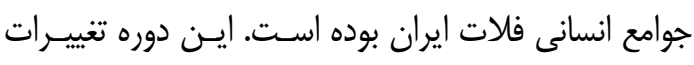

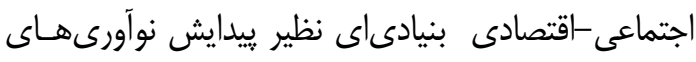

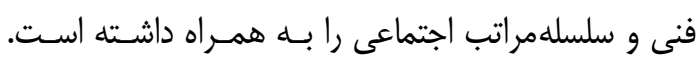

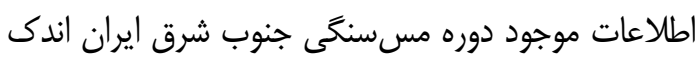

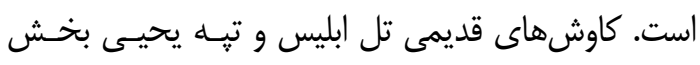

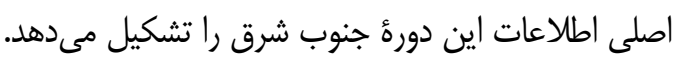

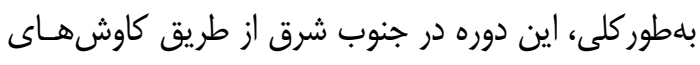

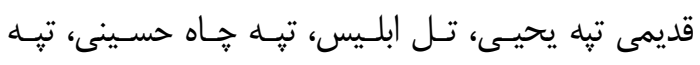

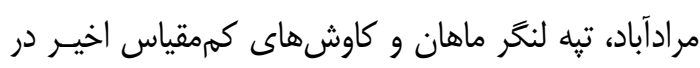
تبه دهنو، تبه دهنو شرقى، محطوط آباد جيرفت، گوررستان

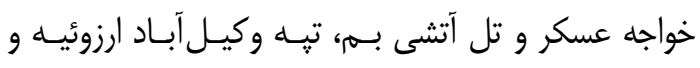

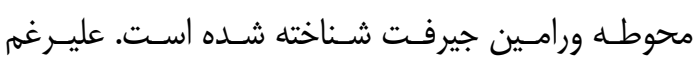
كاوشهاى صورت كرفتـهـ در ايـن محوطـهـهـا، كماكـان 


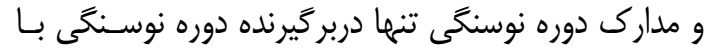

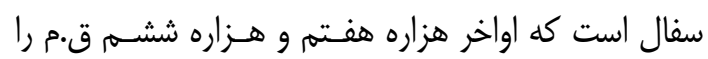

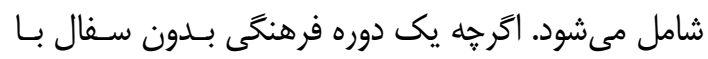

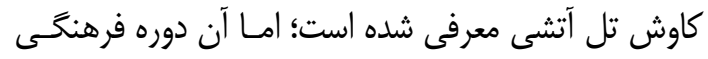
نهتنها مقدم بر دوره نوسنكى با سفال منطقه نبـوده، بلكـهـ

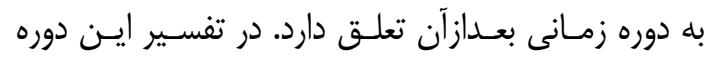

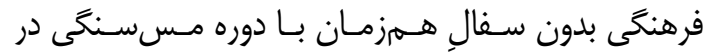

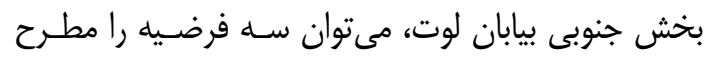

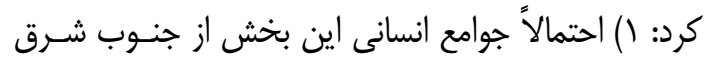

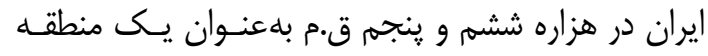

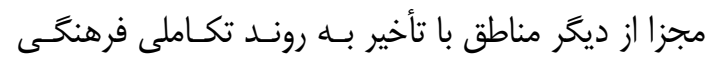

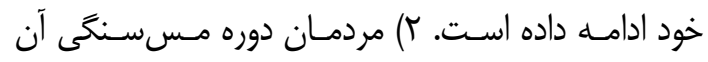

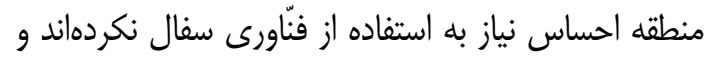

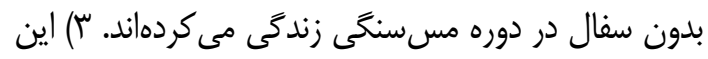

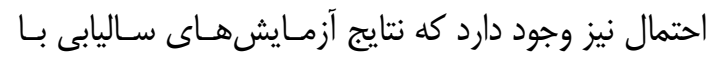

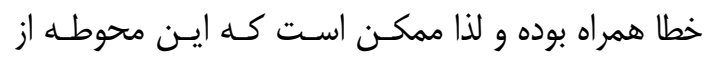
قدمت بيشترى برخوردار باشد.

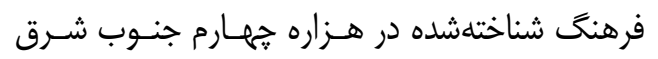

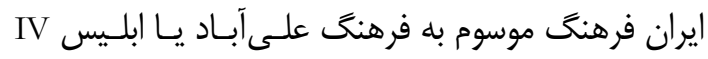

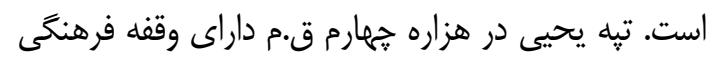

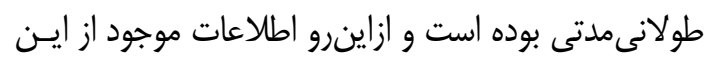
هزاره در دشت صوغان و حـوزه شـاه مـاران -دولـت آبـاد جندان زياد نيست. در دشـت بردسـير فرهنــ على على آبـاد

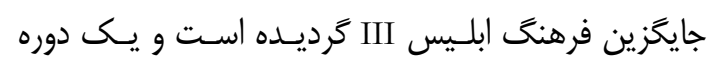

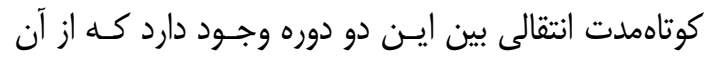

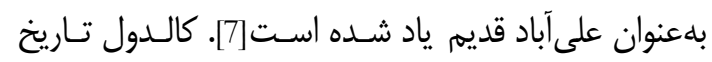

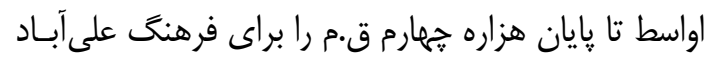

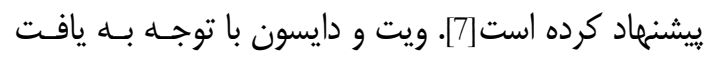

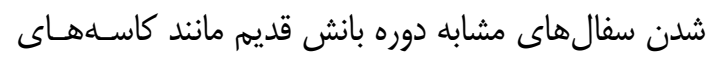

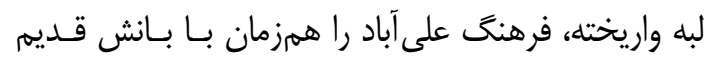

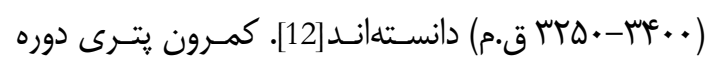

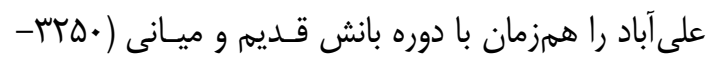

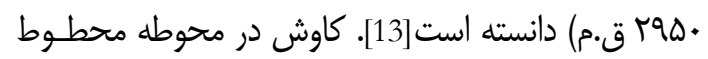

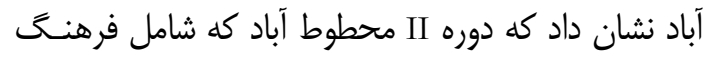

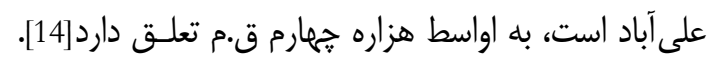

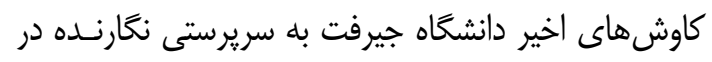
محوطه ورامين جيرفت نيز همين تاريخ يعنى اواسط هزاره
دوره يحيى VA را به اواخر هـز اره هـنجهم و اوايـل هـز اره

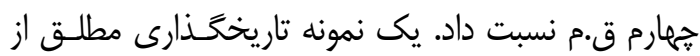

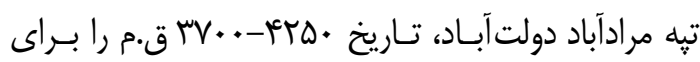

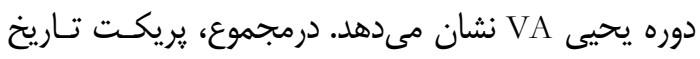

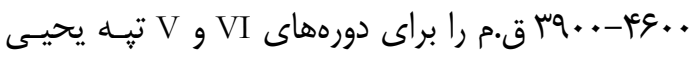

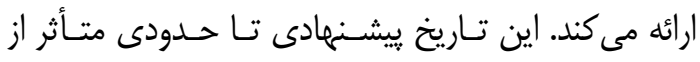

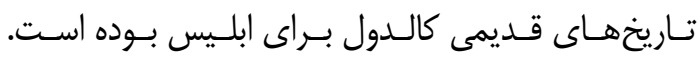

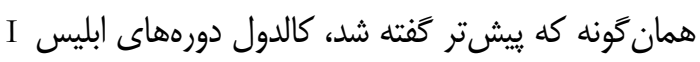

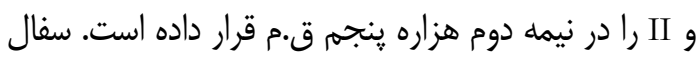

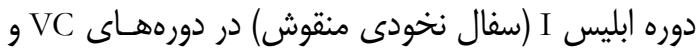

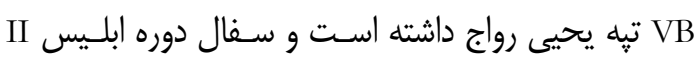

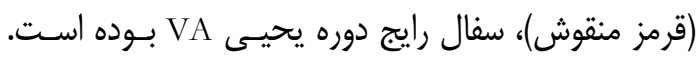

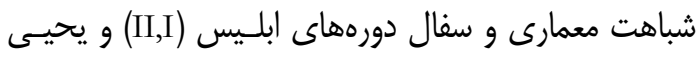
(VC,B,A)

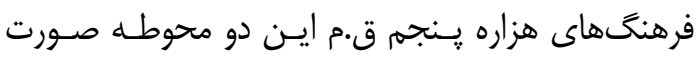

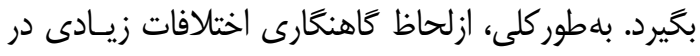

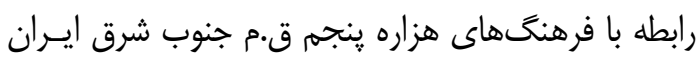

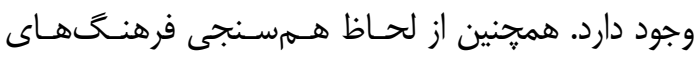

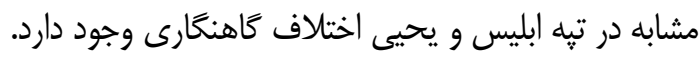

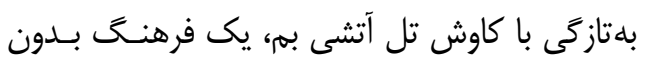

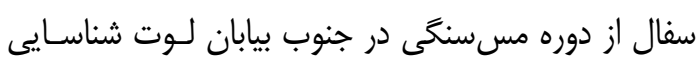

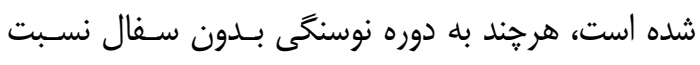

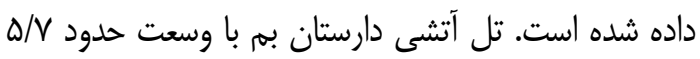

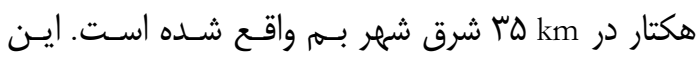

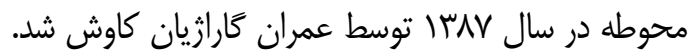

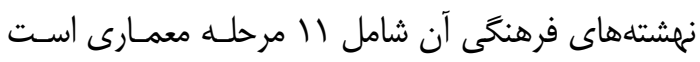

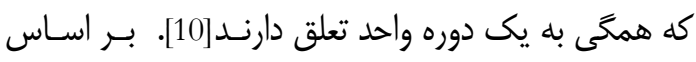

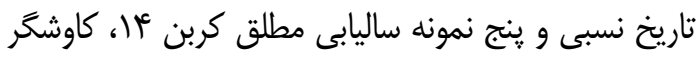

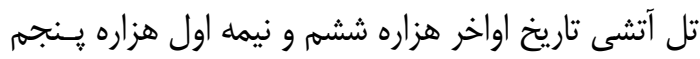

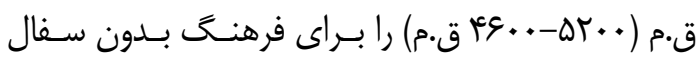

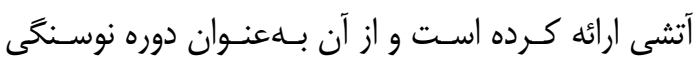

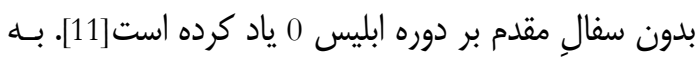

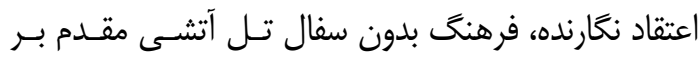

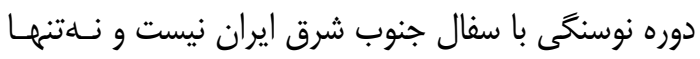

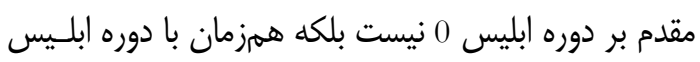

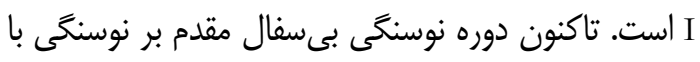

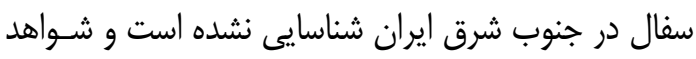

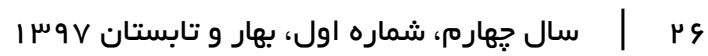


شهداد قرار دارد. اين محوطه بيش از بيست هكتار وسـعت

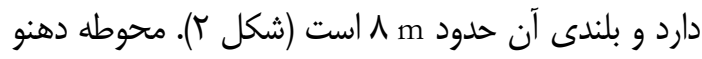

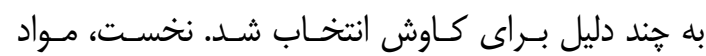
فرهنگى سطحى نشان مىداد كه دربردارنده استقر ارهايى

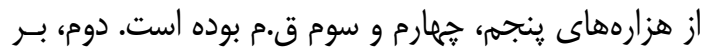

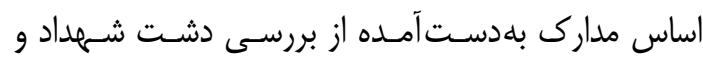
ملاحظات نظرى، ما بر ايسن بـاور بـوديم كـهـ تِّهـ دهنـو

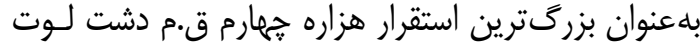

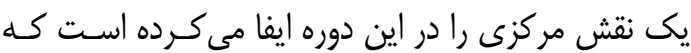

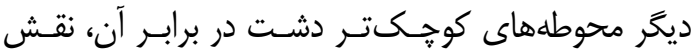

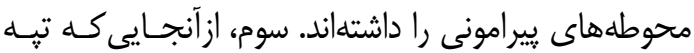

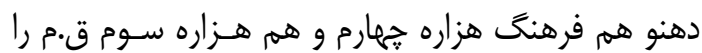
شامل مىشد، اين امكان را فراهم مىكرد تا فرايند انتقـال

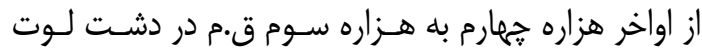

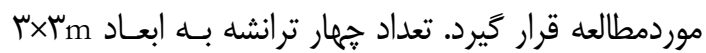
در اين محوطه مورد كاوش قرار گرفت (شكل بّ) و از هـر

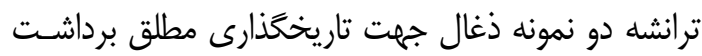

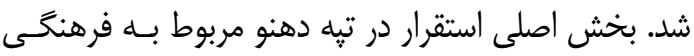

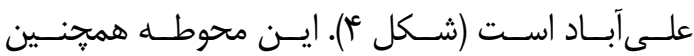

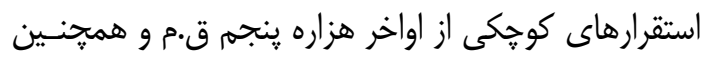

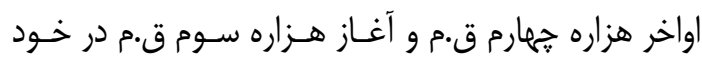

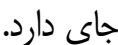

جهارم ق.م را براى فرهنگ على آبـاد تائيـد كـرد. نسـبت

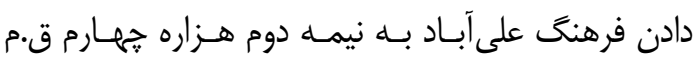
توسط اكثر محققان، به دليل يافت شـدن مـواد فرهنخـى دوره بانش قديم مانند كاسـهـهـاى لبـه واريختـه در لايـهـ

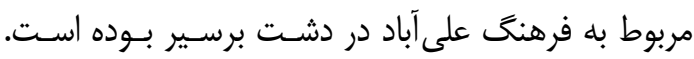

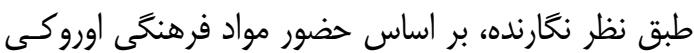

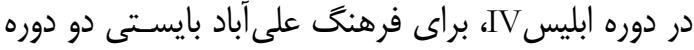

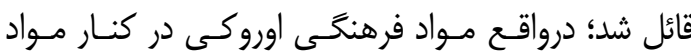

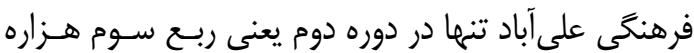

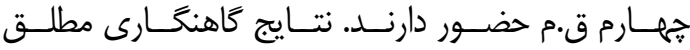

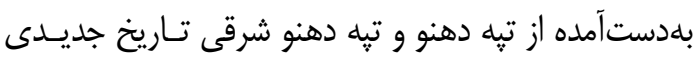

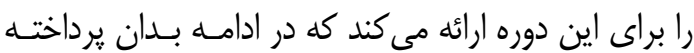

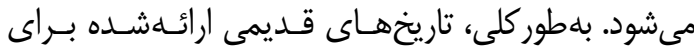

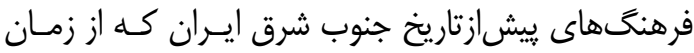

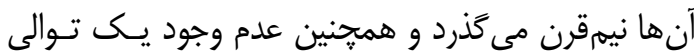

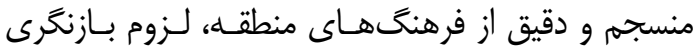
كاهنگارى جنوب شرق ايران را دوجندان مى كند.

" إ. مواد و روشها ץ-1. معرفى محوطه ا. مواى و باستانى موردمطالعه و كَاهنغارى نسبى آنها

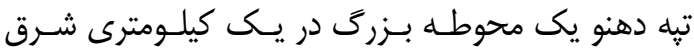

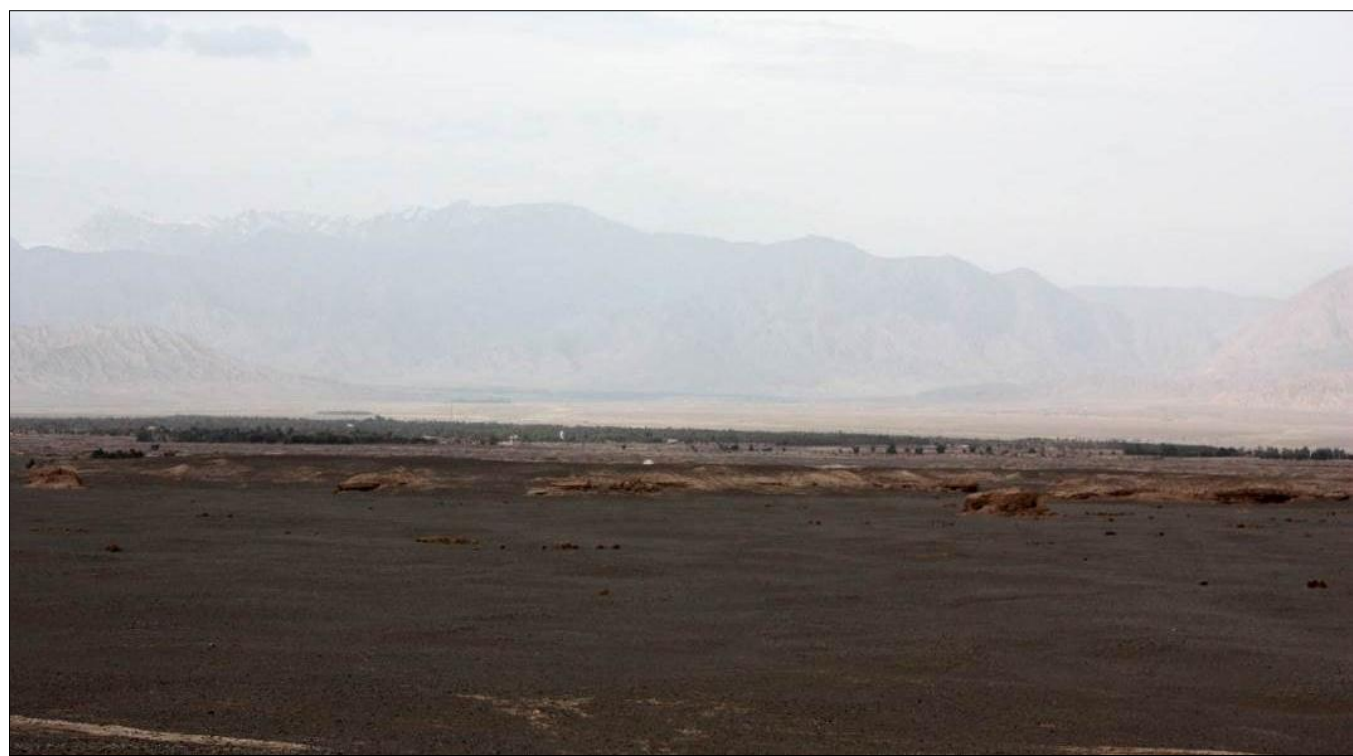

شكل r: تيه دهنو و منظر كاه طبيعى بيرامونش در بخش پايانى مخروطافكنه شهداد Fig. 2: Tepe Dehno and its surrounding landscape

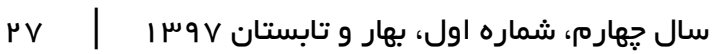




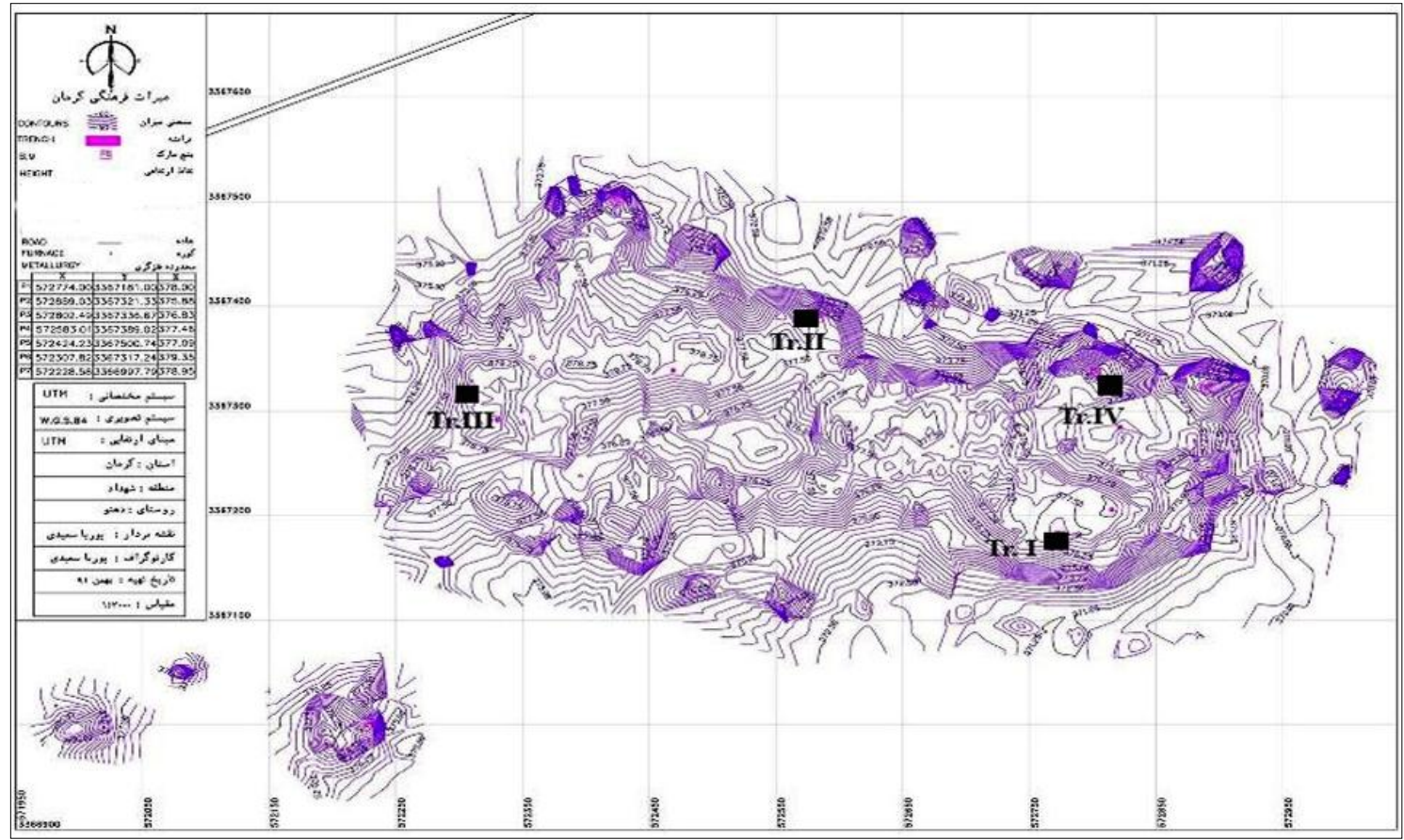

شكل سا: نقشه تويوگًرافى تِه دهنو و محل ترانشههاى آن

Fig. 3: Topographic map of Tepe Dehno and the excavated areas

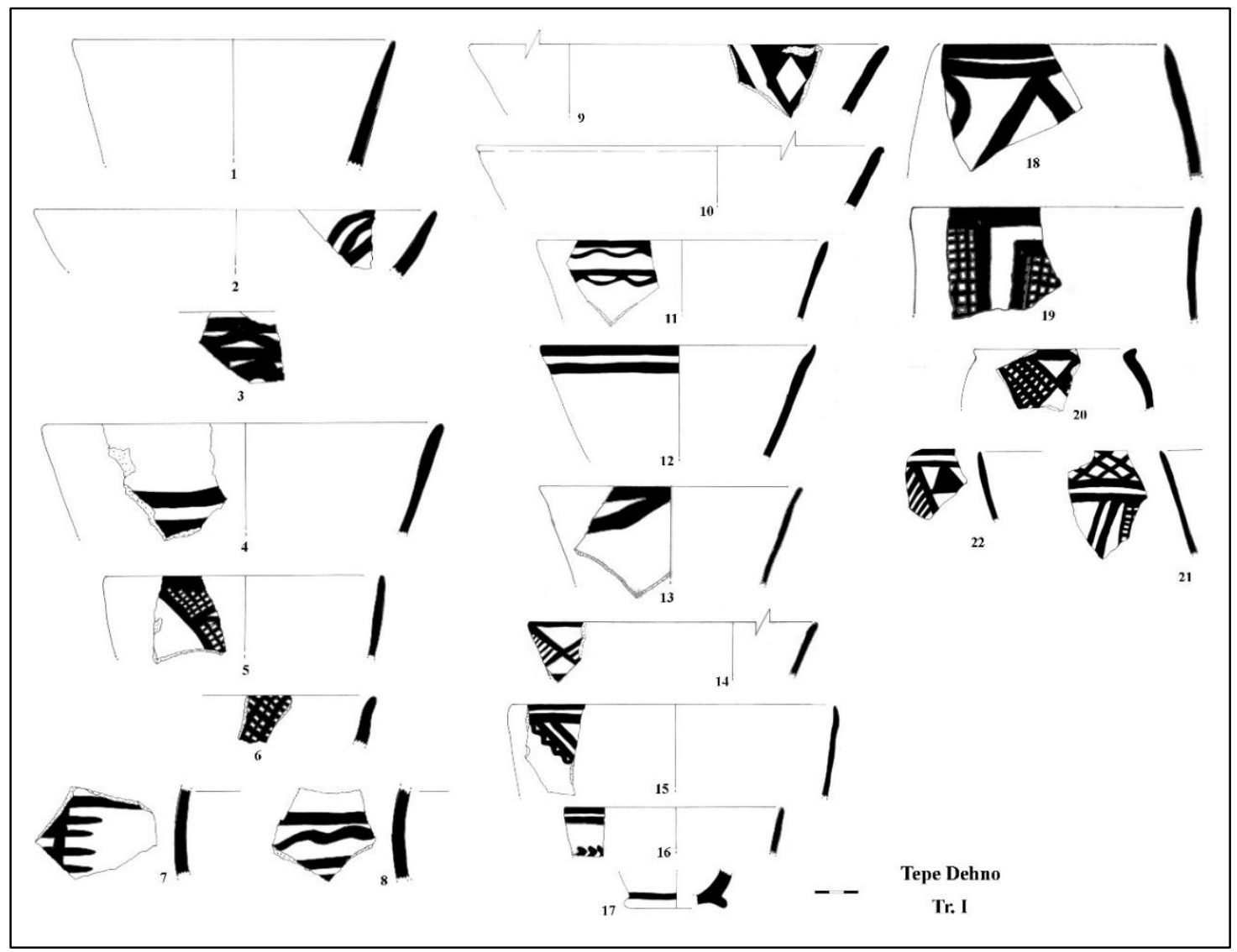

شكل ع: نمونه سفال هاى فرهنگ على آباد بلهدستآمده از تِه دهنو شهداد

Fig. 4: A collection of the ceramics of Aliabad culture recovered from Tepe Dehno 


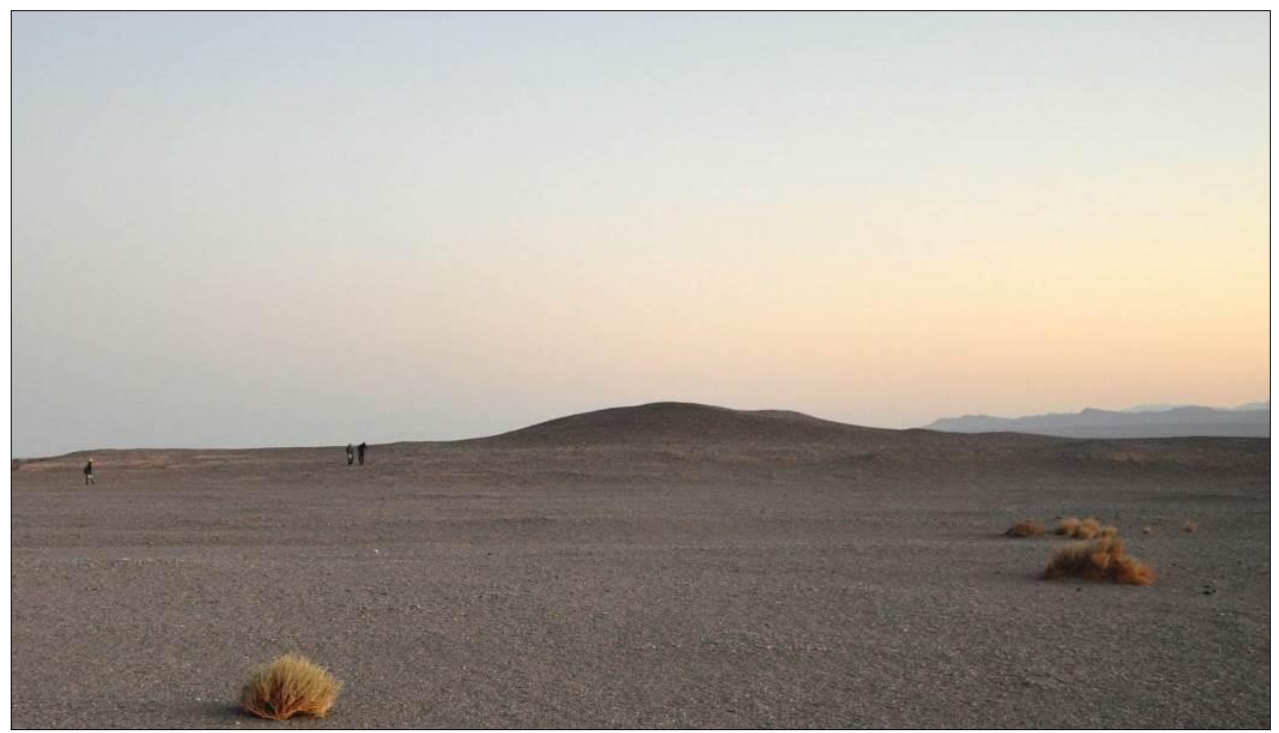

شكل ه: دورنماى تيه دهنو شرقى، ديد از شمالشرق

Fig. 5: General view of Tepe East Dehno, taken from NE

راهبرد در انتخاب نمونهها بدين گَونه بود كه يك تـوالى از

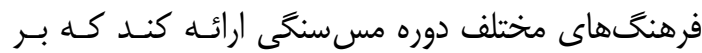
همين اساس تاريخخذارى انجامشــه از تِـهـ دهنــو و تبـهـ

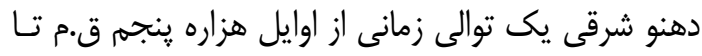

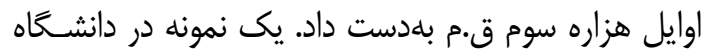
بلفاست ايرلند (شـكل BF) و 9 نمونسه ديخـر در دانشـاه

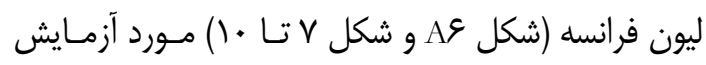

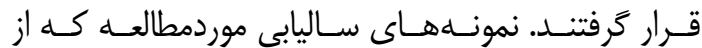

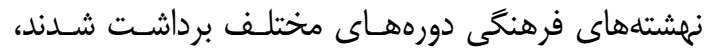

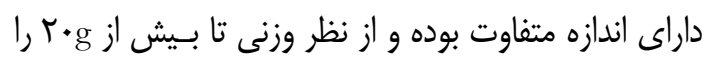

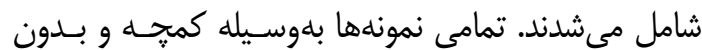

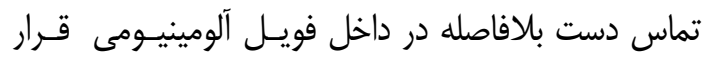

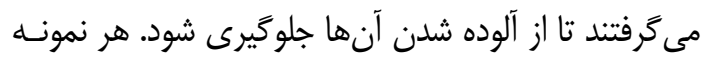

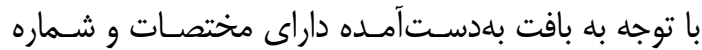

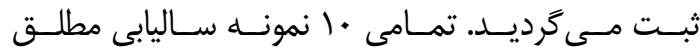

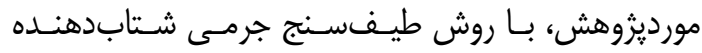
مـورد آزمايش قـرار (Accelerator Mass Spectrometer)

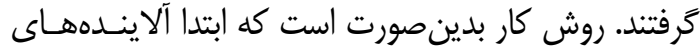

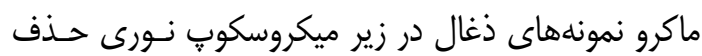

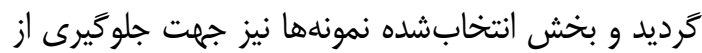
هر گونه منبع احتمالى آلودىى شيميايى مورد ياكسازى قرار

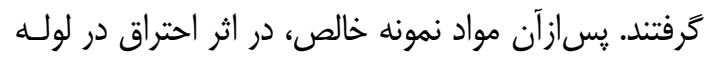

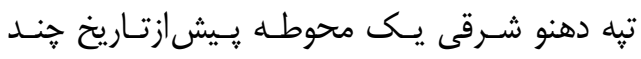

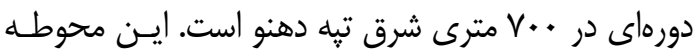

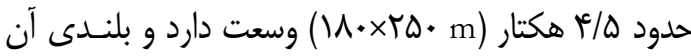

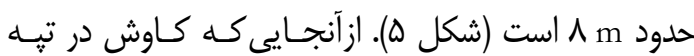
دهنو منجر به دستيابى به قديمىترين استقرارهاى دشـت شهداد نشد، تبه دهنو شرقى بدين منظـور مـورد كـاوش

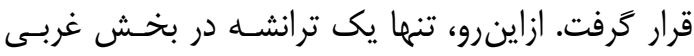
محوطه يعنى جايى كه مواد سـطحى نشـان مسى داد بــهـ هزاره קنججم ق.م تعلق دارد، كاوش شد. از ايـن محوطـهـ

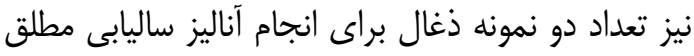

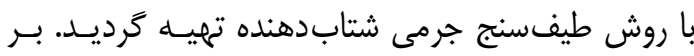
اساس كاهنگارى نسبى مبتنى بر مقايسه سفالى، فرهنگ

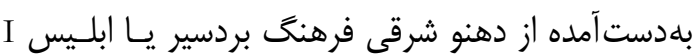

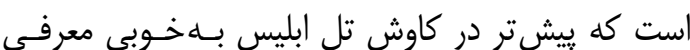
شده است.

\section{ז-r. روش هاى نمونهبردارى و تاريخَذارى مطلق كربن fl اله روش AMS}

بلمنظور دست يابى به اهداف يزوهش موردنظر، تعـداد +1 نمونه ذغال از جهار ترانشه كاوش شده در تِّه دهنو و يك ترانشه كاويده شده در تيه دهنو شـرقى مـورد آنـاليز قـرار

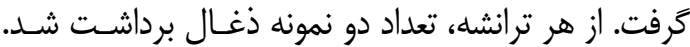

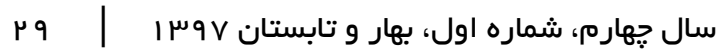


مواد و شاخصهاى استاندارد عرضهشــه توسـط آزانـس

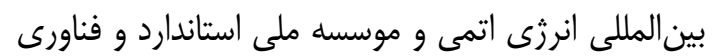
مشـخص مسى

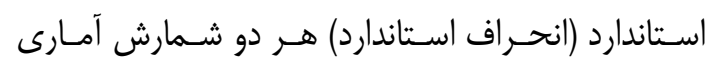

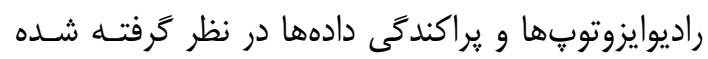

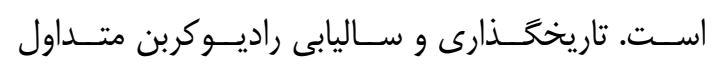
نمونههاى تيه دهنو و دهنو شرقى با استفاده از نرمافـزار

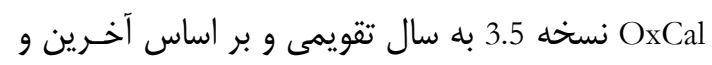

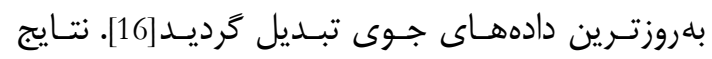

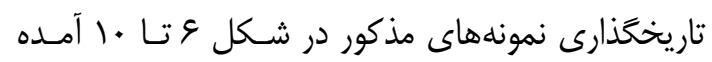
است.
دربسـته كـوارتز بـهـ دى اكسـيدكربن تبــيل شـــ. دى

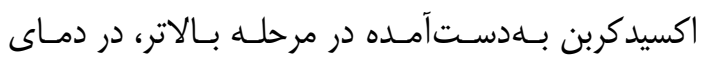

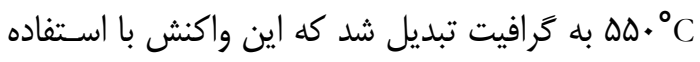
از هيدروزن با خلـوص بسـيار بـالا بـهعنـوان كاتـاليزور

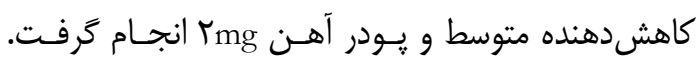
يسازاين مرحله نمونهها به دليل دارا بودن عنصر گرافيت

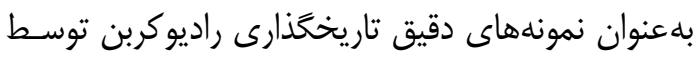
طيفسنج جرمى شتابدهنده مورداستفاده قـرار زرفتنـد.

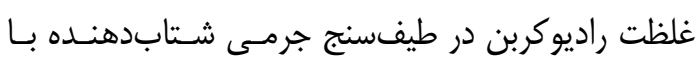

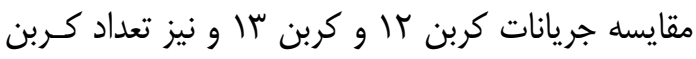
؟الهايى كه از نمونههاى موردمطالعه به دست مى آيسـد و
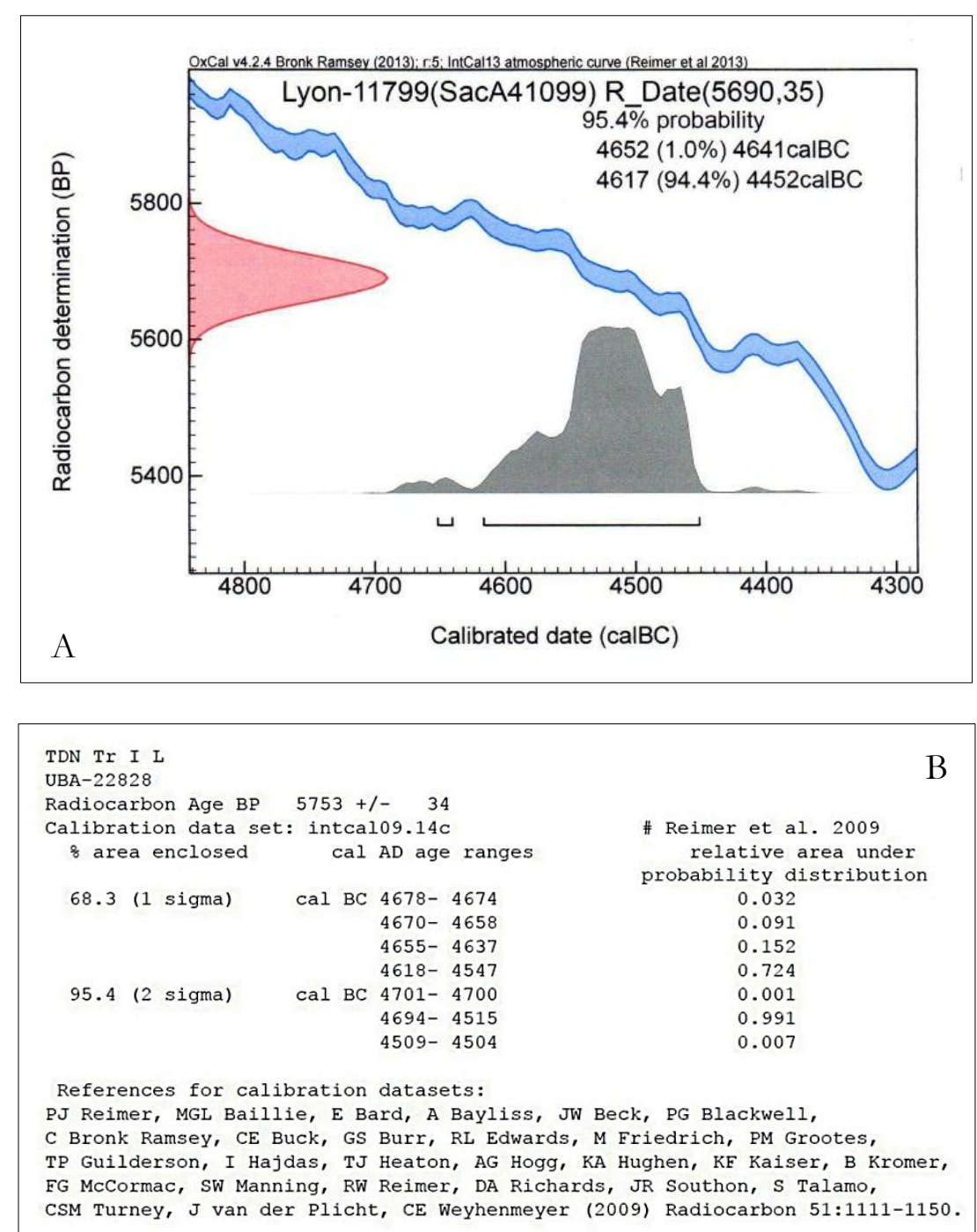

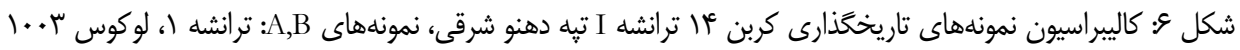

Fig. 6: ${ }^{14} \mathrm{C}$ date from Tepe East Dehno, A,B: Trench 1, Locus 1003 


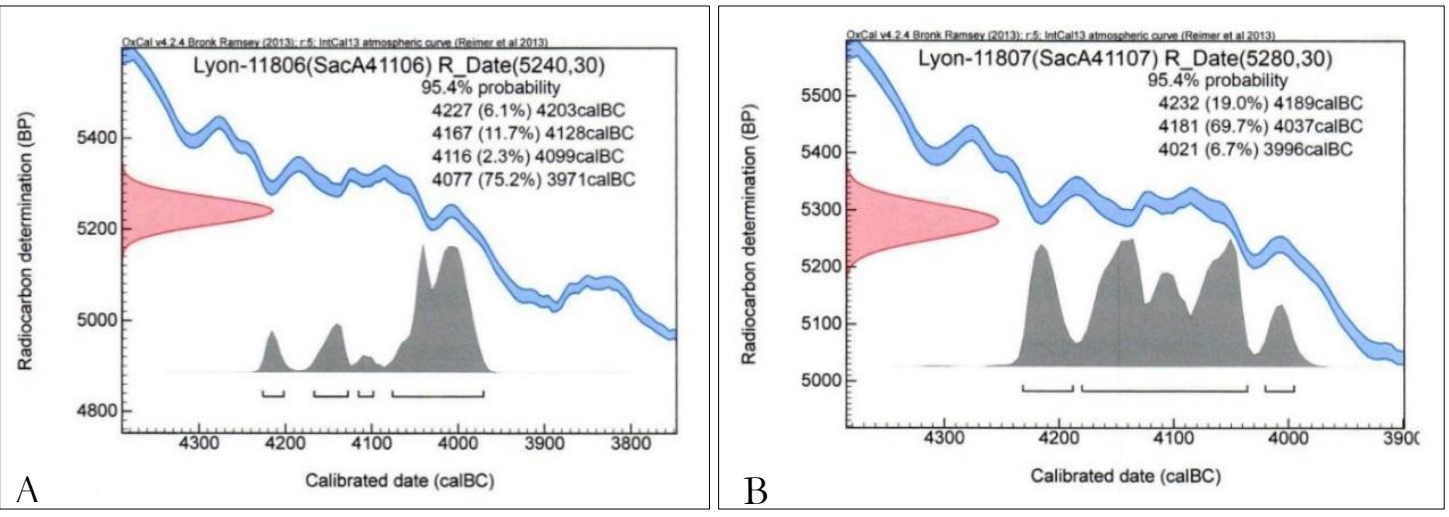

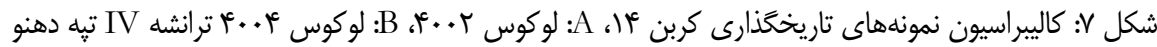

Fig. 7: ${ }^{14} \mathrm{C}$ dates from Tepe Dehno, Trench IV, A: Locus 4002, B: Locus 4004
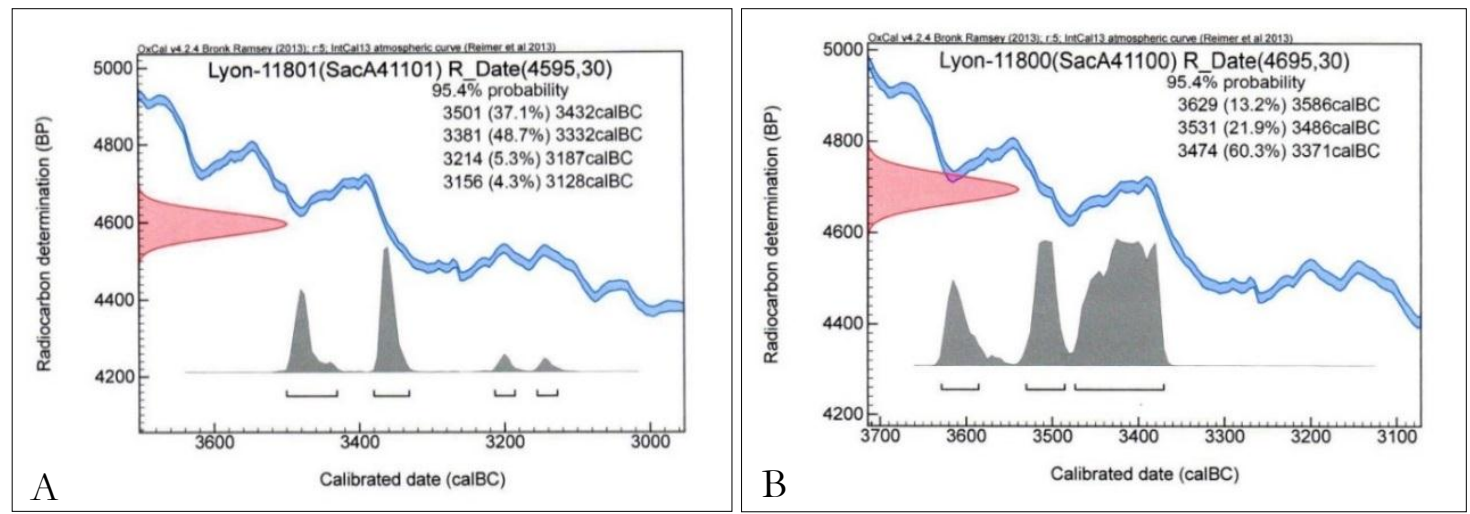

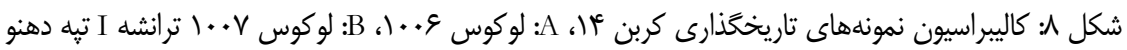

Fig. 8: ${ }^{14} \mathrm{C}$ dates from Tepe Dehno, Trench I, A: Locus 1006, B: Locus 1007
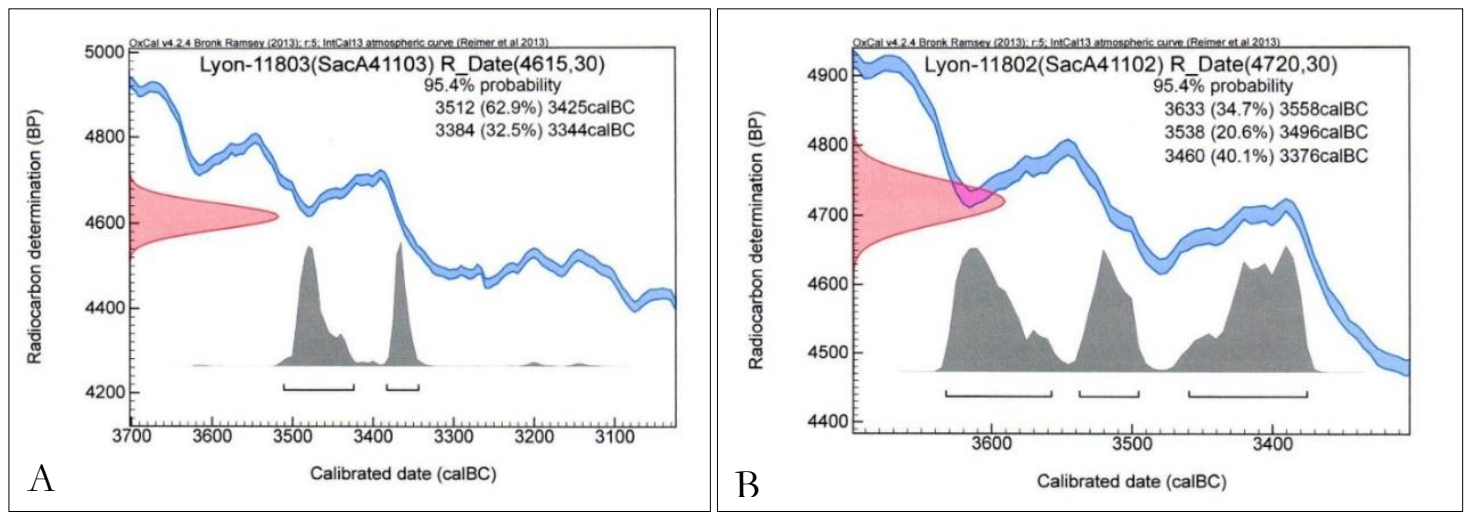

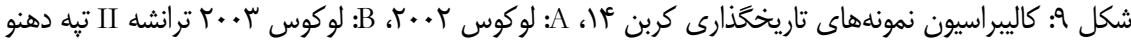

Fig. 9: ${ }^{14} \mathrm{C}$ dates from Tepe Dehno, Trench II, A: Locus 2002, B: Locus 2003

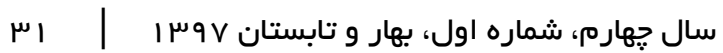



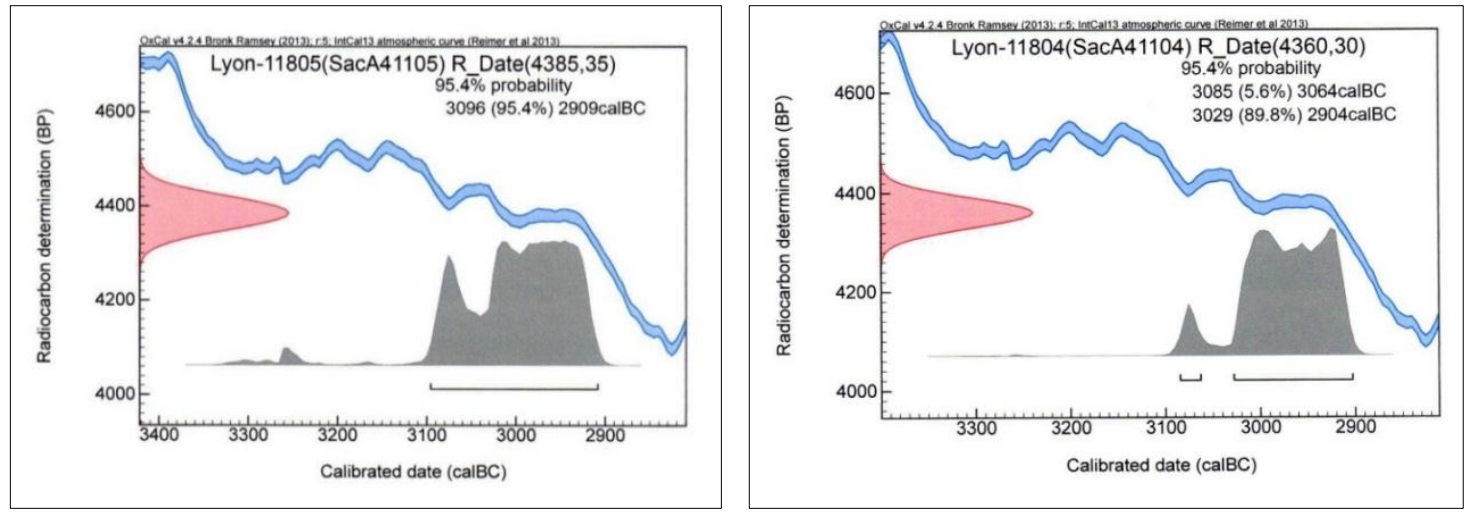

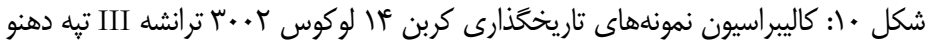

Fig. 10: ${ }^{14} \mathrm{C}$ dates from Tepe Dehno, Trench III, Locus 3002

بردسير با نام فرهنگ على آباد (Iblis IV) شناخته مى شود.

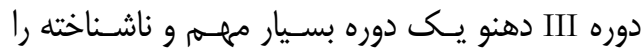
شامل مى شود كه مربوط به سدهاى بإيانى هزاره جهـارم

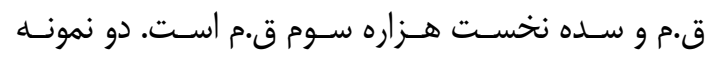

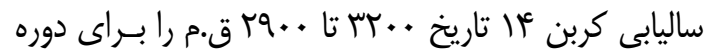
دهنو III نشان مى دهد (شكل • (A,B)).

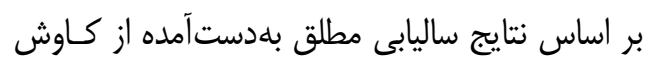
تبه دهنو و دهنو شرقى منطقه شـهداد كاهنگَـارى مطلـق

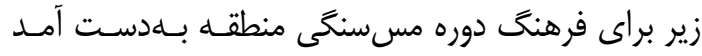

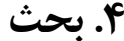

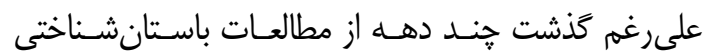

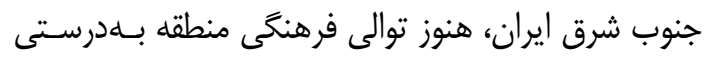

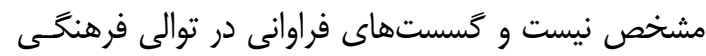
ييشازتاريخ منطقه وجود دارد. افزون بر اين، شناخت ما از

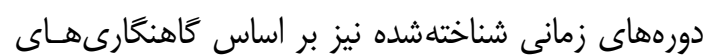

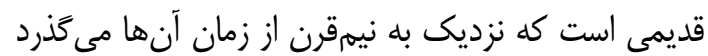
و و بى شكى نياز به بازنخرى دارد.

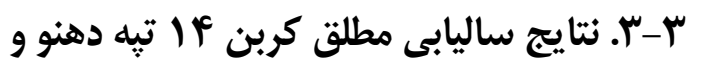
تيه دهنو شرقى

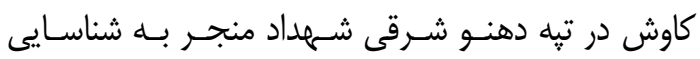

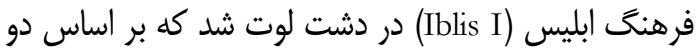

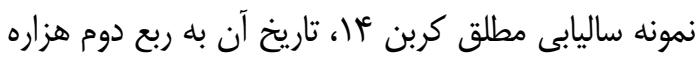

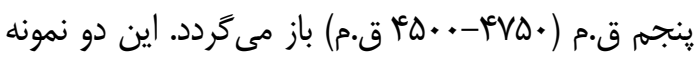

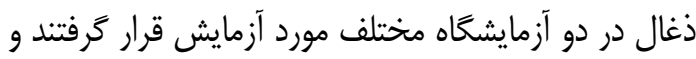

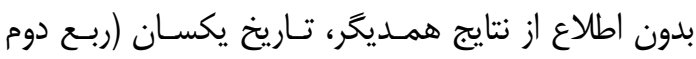
هزاره ينجم ق.م) را نشان دادند (شكل 9 (A,B)).

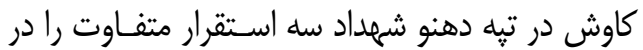

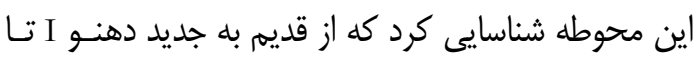

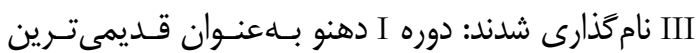

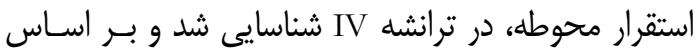

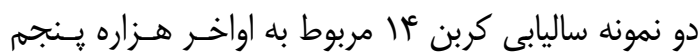

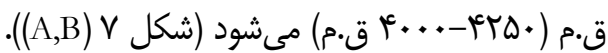

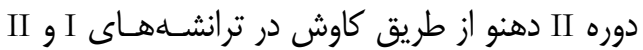

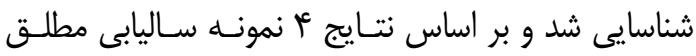

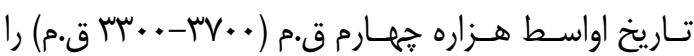

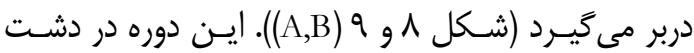

جدول (: دورهبندى و توالى زمانى بهدستآمده از كاوش تيه دهنو شرقى و تِه دهنو شهداد

Table 1: Periodization and chronology of Tepe Dehno and East Dehno

\begin{tabular}{|c|c|c|c|}
\hline Period & Excavated Site & Known Culture & Absolute Date BC \\
\hline East Dehno & Tepe East Dehno & Bardsir & $4750-4500$ \\
\hline Dehno I & Tepe Dehno & - & $4250-4000$ \\
\hline Dehno II & Tepe Dehno & Aliabad & $3700-3300$ \\
\hline Dehno III & Tepe Dehno & - & $3200-2900$ \\
\hline
\end{tabular}


ارائه كرد (جدول (). اين در حالى است كه كاللدول تـاريخ

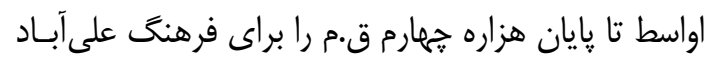

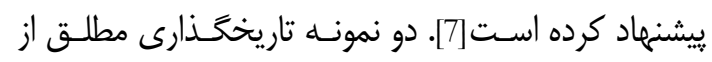
محوطه محطوط آباد جيرفت نيز تاريخ مطلـق تِّهـ دهنـو

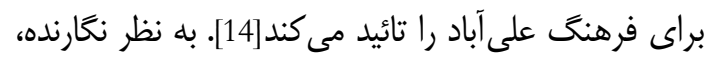

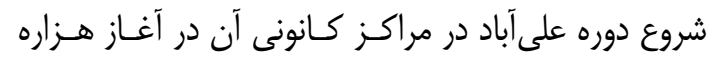

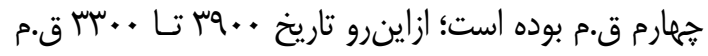

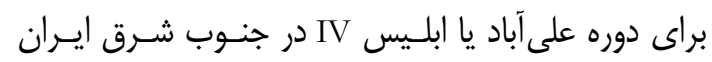

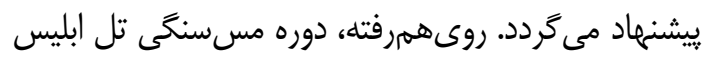
بر اساس نتايج تاريخكذارى مطلق بهدست أمده از منطقـهـ

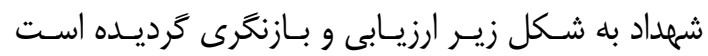

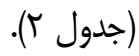
با توجه به اينكه بين فرهنگَهاى دوره مـسســنَّى در تبه يحيى و تل ابليس همبستخى فرهنكَى وجـود دارد،

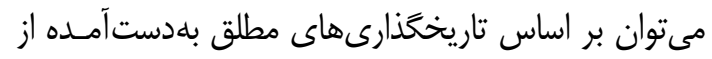
منطقه شهداد، كاهنكارى هاى قـديمى تِّهـ يحيـى را نيـز

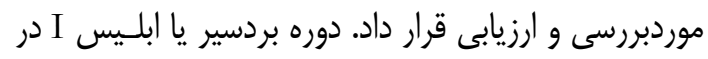

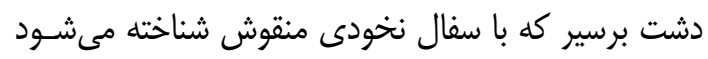

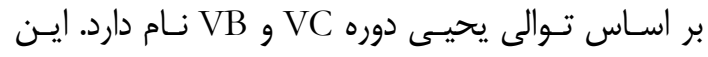

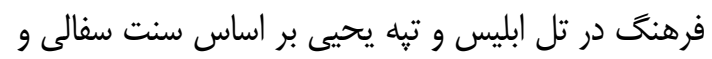

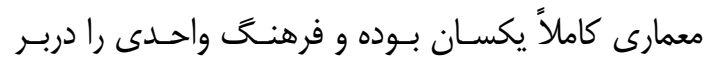

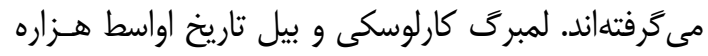

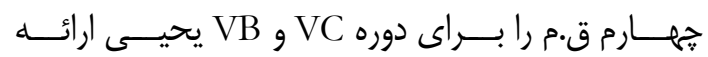

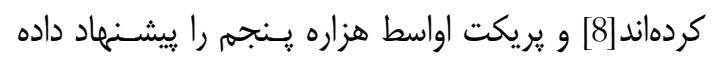

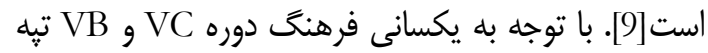

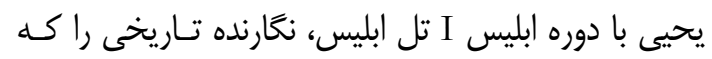

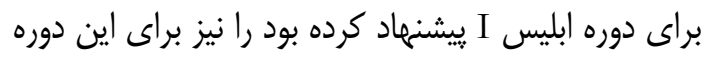

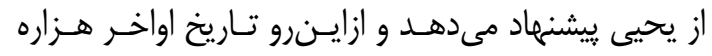

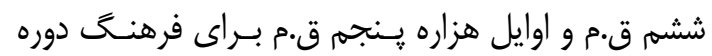

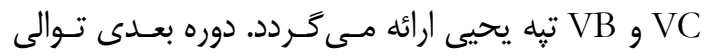
يحيى، دوره VA است كه فرهنگ دربردارنده سفال قرمز
بر اساس اطلاعات ييشـين، جـدول كاهنگــارى دوره

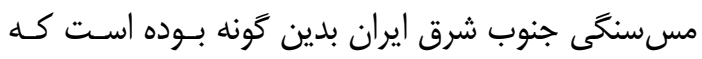

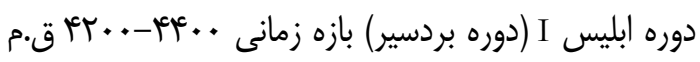

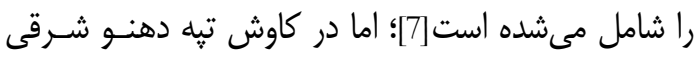

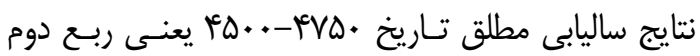

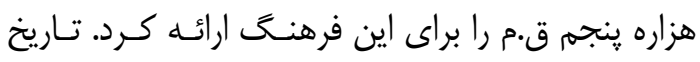

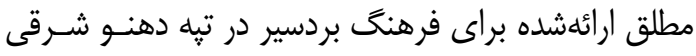

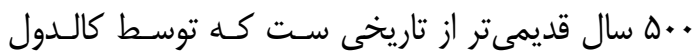

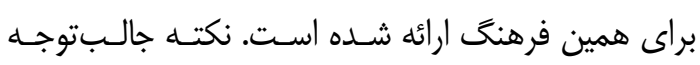
اينكه منطقه شهداد يعنى جايى كه تبه دهنو شرقى در آن آن

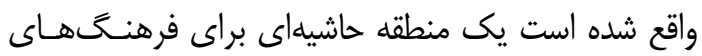
دوره مس سنكى در جنوب شرق ايران است. منطقه شهرداد

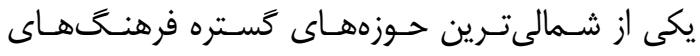

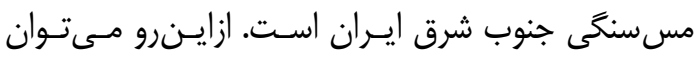

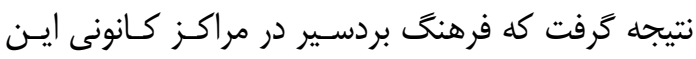

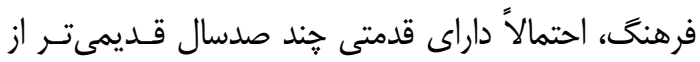

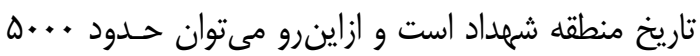

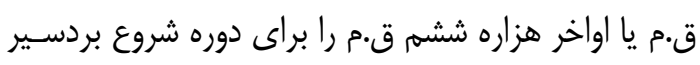

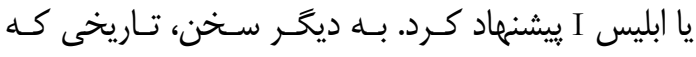

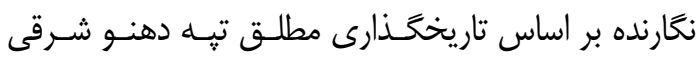

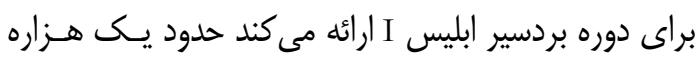

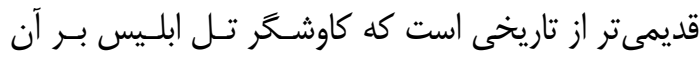

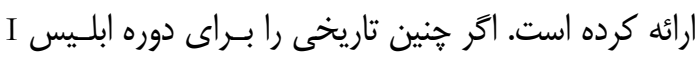

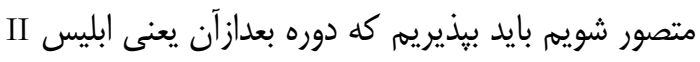

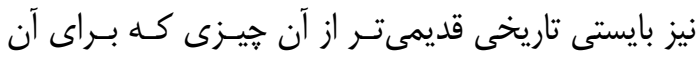

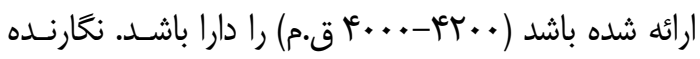

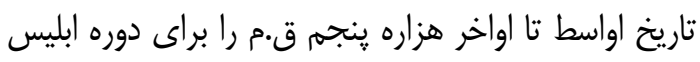

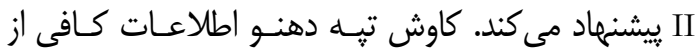
تاريخگذارى دوره على آباد يا ابليس IV در اختيار مـا قـــار

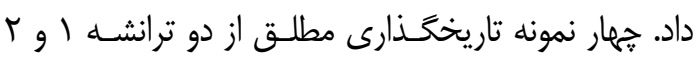

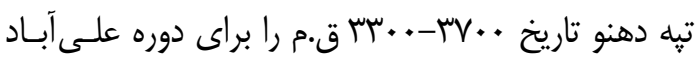

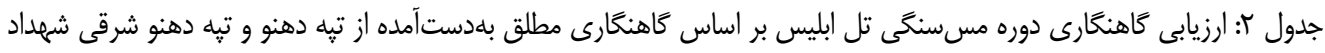
Table 2: Revision of the chronology of the Chalcolithic period of Tal- i Iblis based on Tepe Dehno and East Dehno excavations

\begin{tabular}{|c|c|c|}
\hline Period & Caldwell's Chronology & Proposed Chronology \\
\hline Iblis I & $4400-4200 \mathrm{BC}$ & $5200-4600 \mathrm{BC}$ \\
\hline Iblis II & $4200-4000 \mathrm{BC}$ & $4600-4100$ \\
\hline Iblis IV & $3400-3000 \mathrm{BC}$ & $3900-3300$ \\
\hline
\end{tabular}

$\mu$

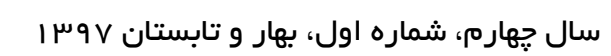




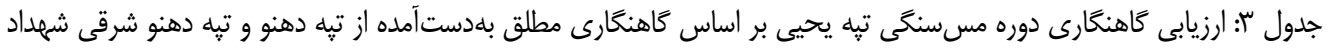
Table 3: Revision of the chronology of the Chalcolithic period of Tepe Yahya based on Tepe Dehno and East Dehno excavations

\begin{tabular}{|c|c|c|c|}
\hline Period & $\begin{array}{c}\text { Proposed Chronology of Lamberg- } \\
\text { Karlovsky and Beale }\end{array}$ & $\begin{array}{c}\text { Proposed Chronology of } \\
\text { Prickett }\end{array}$ & Proposed Chronology of Author \\
\hline VC \& VB & $3900-3300$ BC & Mid 5 $5^{\text {th }}$ millennium BC & $5300-4700$ BC \\
VA & $\begin{array}{c}\text { Late } 5^{\text {th }} \text {-early } 4^{\text {th }} \\
\text { millennium BC }\end{array}$ & $4700-4100$ BC \\
\hline
\end{tabular}

ذغال بهدست آمده از كاوش تبه دهنو و تبه دهنو شـرقى

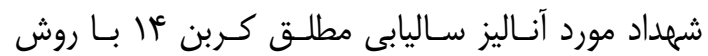

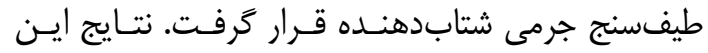

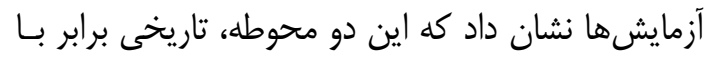

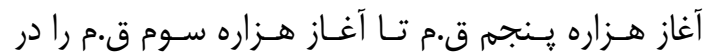

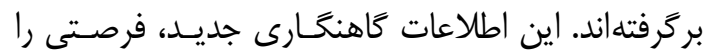

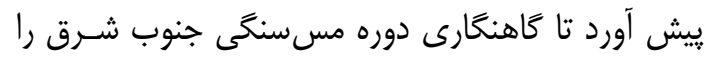

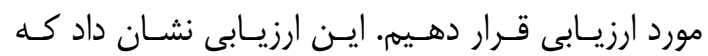

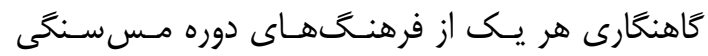

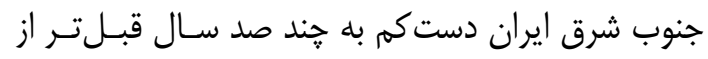

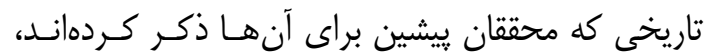

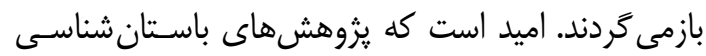

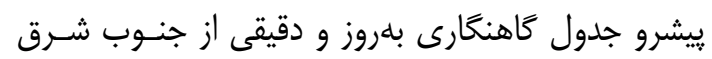

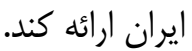

\section{سباسكَز ارى}

نكارنده بر خود لازم مى داند از زحمات تمام كسانى كـه در به سرانجام رساندن كاوش تبه دهنو و دهنو شرقى شهداد

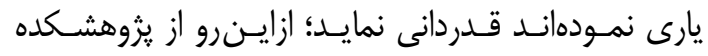

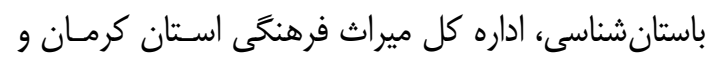

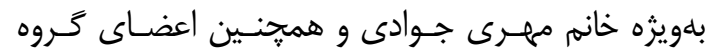

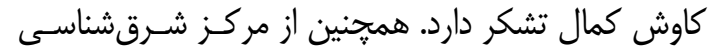

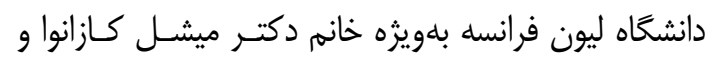

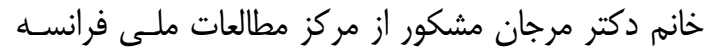

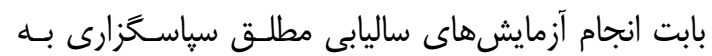
عمل مى آيد.

\section{References}

[1] Eskandari N. 14th season of Dasht-e Lut project: Results of excavations at Tepe Dehno and east Dehno. In: Hessari M, editor. Pap.

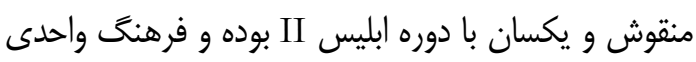

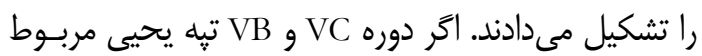

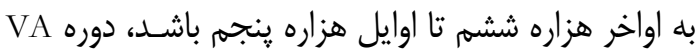

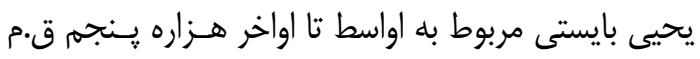

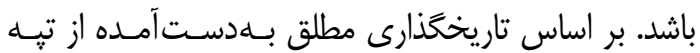

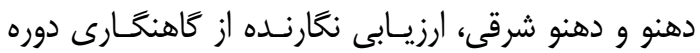

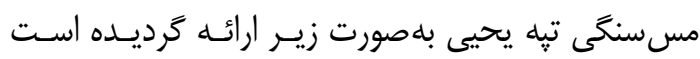

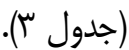

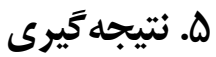

وجود يك خارجوب كاهنگارى دقيق و همجنين شناخت

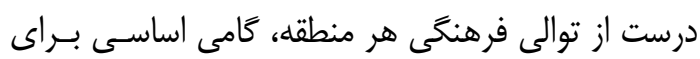

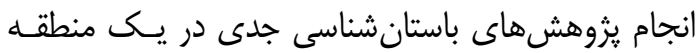

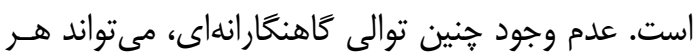
تحليلى در خصوص فرهنگ خطا كند. يكى از خالشهاى امروز باستان شناسى ايـران،

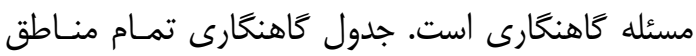

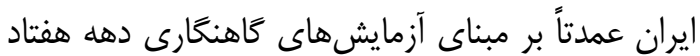

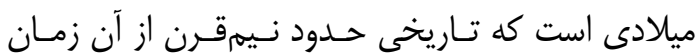

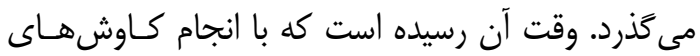

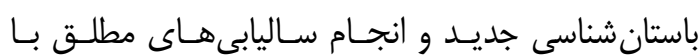
روشهاى ييشرفته مانند طيفسنج جرمى شتابدهنـــه، كاهنكارى هاى ييشين فلات ايـران مـورد ارزيابى قـرار

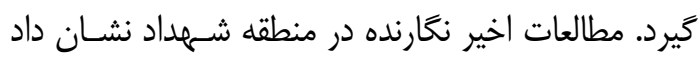

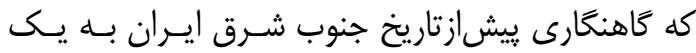

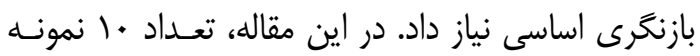

Honor Mir-Abedin Kaboli. Tehran: Research institute of cultural heritage \& tourism; 2017, p. 73-94. [in Persian]

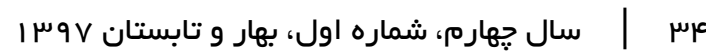




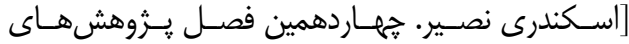

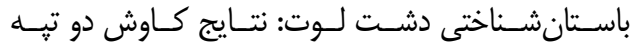

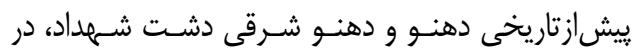

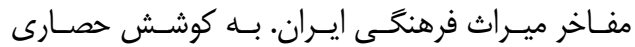

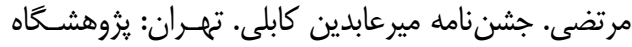

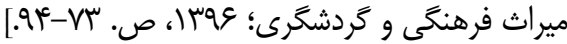

[2] Hakemi A. Aight seasons of survey and excavation at Shahdad. In: Mousavi M editor. Tehran: Research institute of cultural heritage \& tourism; 2006. [in Persian]

[حاكمى على. ززارش هشت فصل بررسى و كـاوش در

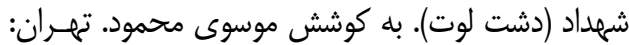

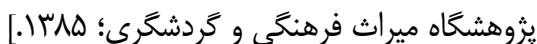

[3] Hakemi A. Shahdad: archaeological excavations of a bronze age center in Iran. vol. 27. IsMEO; 1997.

[4] Kaboli M. Report of the 10th season of excavation at the ancient site of Shahdad, Archaeological reports N.1. Tehran: Cultural Heritage, Handicrafts and Tourism Organization of Iran; 1997, p. 87-124. [in Persian]

[كـابلى ميرعابــدين. گَـزارش دهمــين فصـل كـاوش گــروه

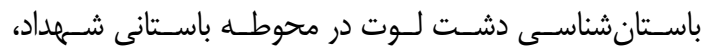

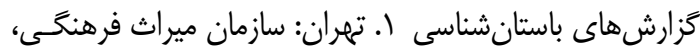

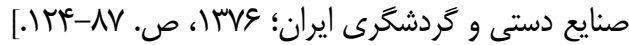

[5] Kaboli M. Report of the twelfth season of excavation at the ancient site of Shahdad. Pajoheshnameh, Tehran: Cultural Heritage, Handicrafts and Tourism Organization of Iran; 2001, p. 239-266. [in Persian]

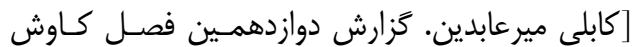

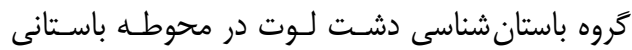

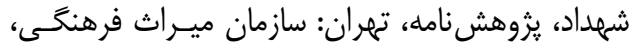

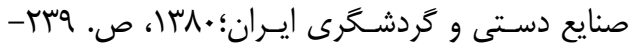

[. T\&9

[6] Kaboli M. Report of the thirteenth season of excavation at the ancient site of Shahdad. Pajoheshnameh, Tehran: Cultural Heritage, Handicrafts and Tourism Organization of Iran; 2002, p. 141-181. [in Persian]

[كابلى ميرعابدين. گزارش يازدهمين فصل كاوش گَروه

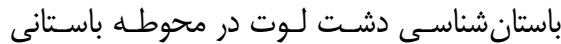

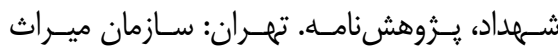

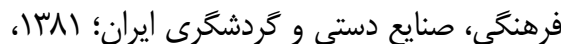

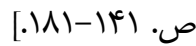

[7] Caldwell JR. Investigations at Tal-i-Iblis (Illinois state museum preliminary reports No.
9). Springf Illinois State Museum Soc 1967.

[8] Lamberg-Karlovsky CC, Beale TW, Adovasio J, Heskel D, Mckerrell H, Meadow RH, et al. Excavations at Tepe Yahya, Iran, 1967-1975. The early periods. Am Sch Prehist Res Bull 1986.

[9] Prickett M. Settlement during the early periods. Excav Tepe Yahya, Iran 1967;1975:215-46.

[10] Garazhian O. Darestan: a group of Pre-pottery neolithic (PPN) sites in south-eastern Iran. Antiquity 2009;83.

[11] Garazhian O, Rahmati M. Period I of Tali-e Atashi: Pre-pottery neolithic culture and architecture in the landscape of SE Iran. Pazhohesh-ha-ye Bastanshenasi Iran 3AD; 2012:111-48. [in Persian]

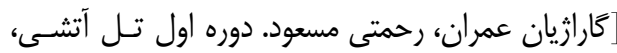

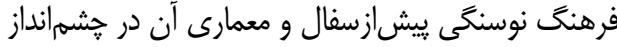

$$
\begin{aligned}
& \text { جنوب شرق ايران. يزوهشهاى باستانشناسى ايـران سان }
\end{aligned}
$$

$[.14 \lambda-11]: 149]$

[12] Nishiaki Y. A radiocarbon chronology for the Neolithic settlement of Tall-i Mushki, Marv Dasht Plain, Fars, Iran. Iran 2010;48:1-10. doi:https://doi.org/10.1080/05786967.2010.1 1864769.

[13] Petrie CA. The Chalcolithic of south Iran. In: Potts D., editor. Oxford Handb. Iran. Archaeol., Oxford: OUP; 2012, p. 120-158.

[14] Vidale M, Desset F. Mahtoutabad I (Konar Sandal South, Jiroft): Preliminary evidence of occupation of a Halil Rud site in the early fourth millennium BC. Anc Iran Its Neighb Local Dev Long-Range Interact Fourth Millenn BC 2013:233-52.

[15] Abedi A. Absolute (14C AMS) and Relative Chronology of Dava Göz Khoy; New Evidence of Transitional Chalcolithic, Dalma and Pisdeli Cultures in NW IRAN. Journal of research on archaeometry. 2016; 2(1):39-54. [in Persian]

$$
\begin{aligned}
& \text { [عابدى اكبر. كاهنغارى مطلـق (14C) و نسـبى محوطـهـ }
\end{aligned}
$$

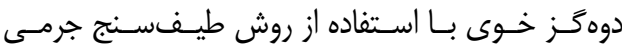

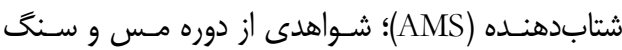

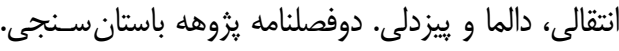

ه ه

[16] Reimer PJ, Baillie MGL, Bard E, Bayliss A, Beck JW, Blackwell PG, et al. Intcal09 and marine09 radiocarbon age calibration curves, 0-50,000 years cal BP. Radiocarbon 2009;51:1111-50. doi:https://doi.org/10. 1017/S0033822200034202. 